\title{
Respiratory Flow Characteristics of Intensive Care Healthcare Workers Performing Patient Care Activities
}

Shawn R. Williamson

srw0044@mix.wvu.edu

Follow this and additional works at: https://researchrepository.wvu.edu/etd

Part of the Occupational Health and Industrial Hygiene Commons

\section{Recommended Citation}

Williamson, Shawn R., "Respiratory Flow Characteristics of Intensive Care Healthcare Workers Performing Patient Care Activities" (2020). Graduate Theses, Dissertations, and Problem Reports. 7859.

https://researchrepository.wvu.edu/etd/7859

This Thesis is protected by copyright and/or related rights. It has been brought to you by the The Research Repository @ WVU with permission from the rights-holder(s). You are free to use this Thesis in any way that is permitted by the copyright and related rights legislation that applies to your use. For other uses you must obtain permission from the rights-holder(s) directly, unless additional rights are indicated by a Creative Commons license in the record and/ or on the work itself. This Thesis has been accepted for inclusion in WVU Graduate Theses, Dissertations, and Problem Reports collection by an authorized administrator of The Research Repository @ WVU. For more information, please contact researchrepository@mail.wvu.edu. 


\title{
Respiratory Flow Characteristics of Intensive Care Healthcare Workers Performing Patient Care Activities
}

\author{
Shawn R. Williamson \\ Thesis submitted \\ To the Benjamin M. Statler \\ College of Engineering and Mineral Resources \\ At West Virginia University \\ In partial fulfillment of the requirements for the degree of \\ Master of Science in \\ Industrial Hygiene
}
Warren Myers, Ph.D., Chair
Kenneth Currie, Ph.D.
Ziqing Zhuang, Ph.D.

Department of Industrial and Management Systems Engineering

\author{
Morgantown, West Virginia
}

2019

Keywords: Respirator, healthcare worker, Industrial Hygiene, respiratory flow, PAPR Copyright 2020 Shawn R. Williamson 


\begin{abstract}
Respiratory Flow Characteristics of Intensive Care Healthcare Workers Performing Patient Care Activities
\end{abstract}

Shawn R. Williamson

In the United States, under OSHA regulations, all respirators used in the workplace must be certified by the National Institute of Occupational Safety and Health (NIOSH). Under current NIOSH standards, loose-fitting powered air-purifying respirators (PAPR) must provide a minimum operational flow of 170 liters per minute. The objective of this study was to characterize the breathing flow rates of nine health care workers during patient care activities typically performed in a hospital's intensive care unit. This characterization will be used to determine the feasibility of lowering the minimum operational flow rate of PAPRS used in health care settings.

Each participant wore a portable respiratory flow recording device during twelve simulated patient care activities. The patient care activities include: changing bedding, turning and positioning the patient, patient health history review, hooking up a cardiac monitor, inserting and starting an IV, drawing blood tubes, patient passive range of motion exercises, inserting setting up and removing a foley catheter, bathing and turning the patient, performing CPR, and inserting and removing a breathing tube.

Of the nine participants, there were four males and five females. The minute volume (MV, L/min), mean inhalation flow (MIF L/min), and peak inhalation flow (PIF L/min) was calculated for each participant during each patient care activity. The mean MV, MIF, and PIF across all participants and patient care activities were 21,50 , and $86 \mathrm{~L} / \mathrm{min}$, respectively. Twosample t-tests were performed to compare the effect of gender on MV, MIF, and PIF. There was a significant difference in MV, MIF, and PIF for males and females $(\alpha=0.05)$. An analysis of variance was conducted to compare the effect of participant and activity on MV, MIF, and PIF. Both participant and patient care activity had a significant effect on the mean MV, MIF, and PIF $(\alpha=0.05)$. A post hoc analysis of the effect of participant and activity on MV, MIF, and PIF was performed through a Tukey HSD test. The results of this study illustrate that lowering the required minimum operational flow of PAPRs may be feasible; however, participant does have a significant effect on breathing flow characteristics. Thus, further analysis is needed to incorporate, correlations between age, weight, body surface area, and body mass index 


\section{Acknowledgement}

I would like to express my deepest appreciation to my committee chair, Dr. Warren Myers, who has expertly guided me through my graduate education and this research. Without his unwavering support and guidance, this research would not have been possible. Also, I would like to thank my committee members, Dr. Ziqing Zhuang, and Dr. Kenneth Currie for their support and guidance.

In addition, I would also like to acknowledge all the healthcare workers who volunteered to participate in this research. Finally, I would like to express a sincere thank you to West Virginia University and NIOSH for supporting this research. 


\section{Table of Contents}

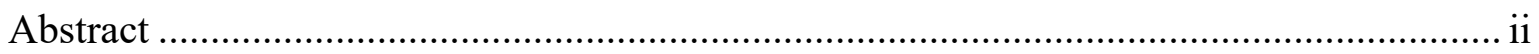

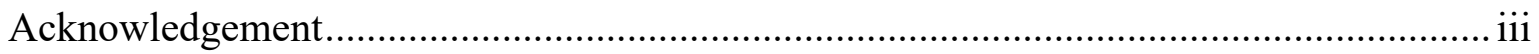

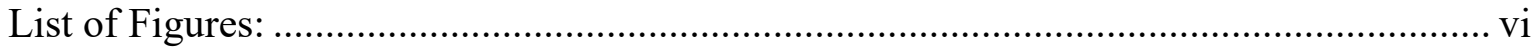

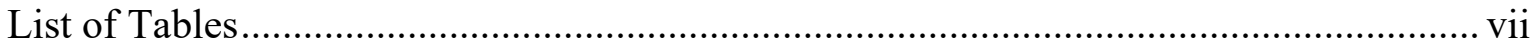

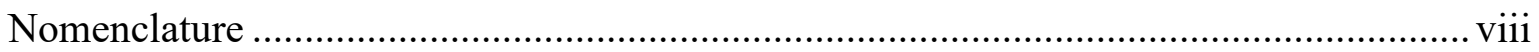

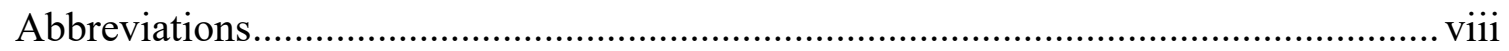

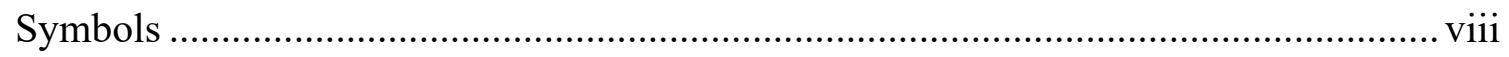

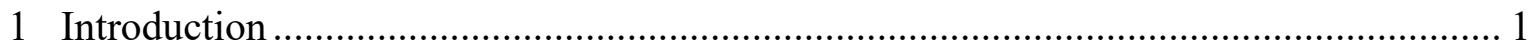

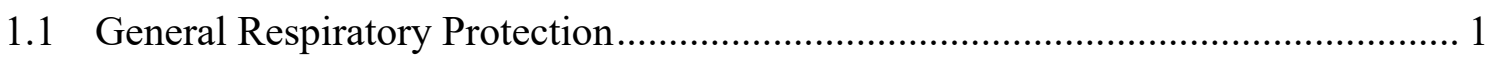

1.1.1 Respirator Approvals and Regulations ......................................................... 1

1.1.2 Particulate Filter Classifications ............................................................ 2

1.1.3 Assigned Protection Factor........................................................................ 2

1.1.4 Respirator Fit-Testing .......................................................................... 3

1.2 Powered Air Purifying Respirators ......................................................................... 3

1.3 Powered Air Purifying Respirators in Healthcare ………………........................... 4

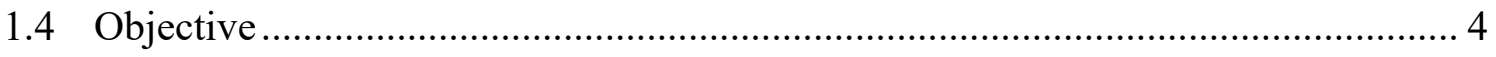

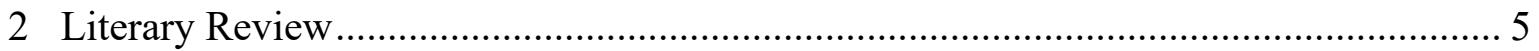

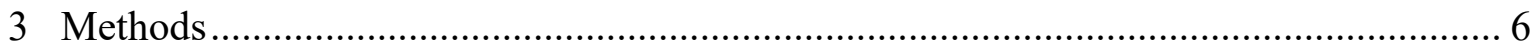

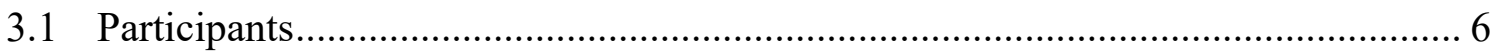

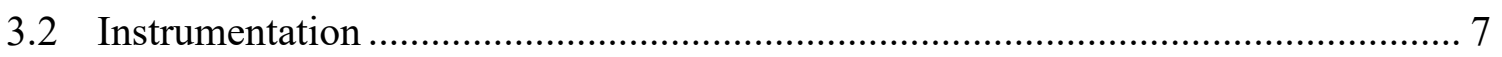

3.2.1 Pressure Data Logger Calibration................................................................ 7

3.3 Experiment Design and Procedure...................................................................... 9

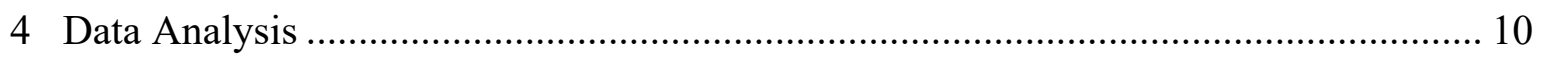

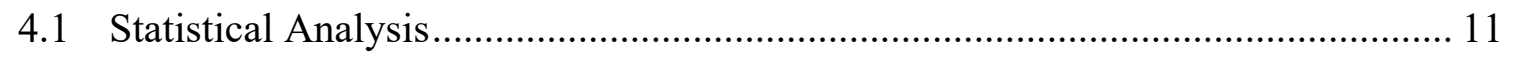


5 Results and Discussion...................................................................................... 12

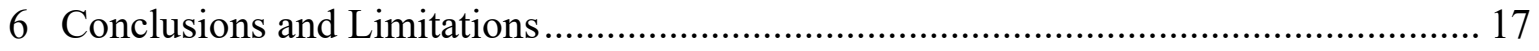

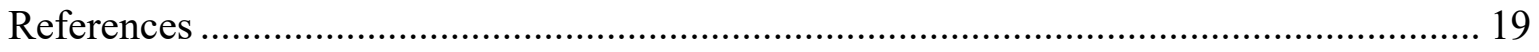

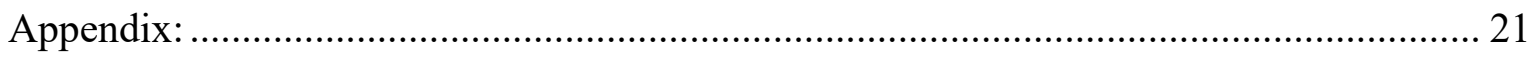

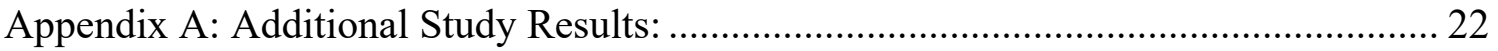

Appendix B: Additional Respiratory Flow Data Graphs........................................... 33

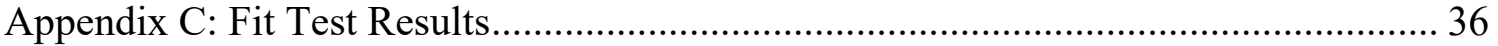




\section{List of Figures:}

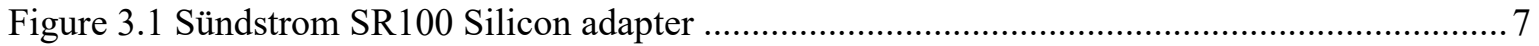

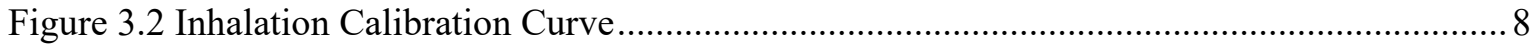

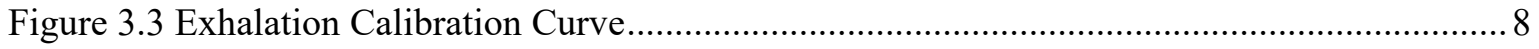

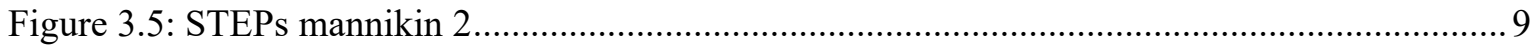

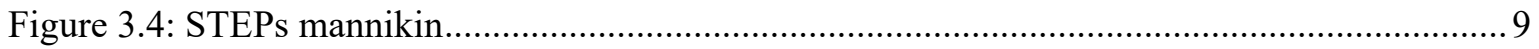

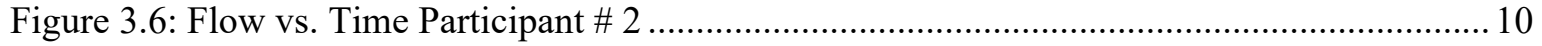

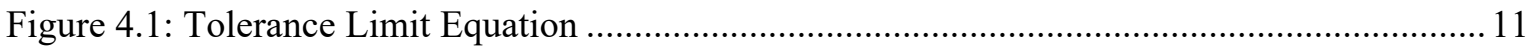




\section{List of Tables}

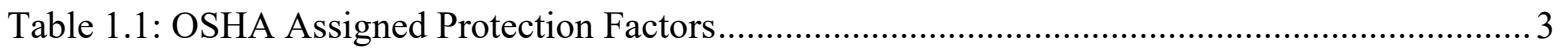

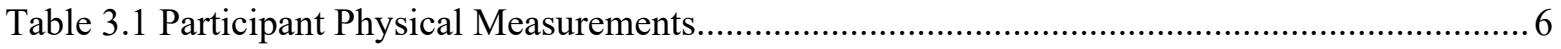

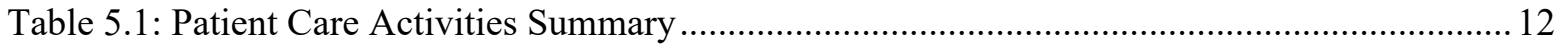

Table 5.2: Participant MV, MIF, and PIF and One-sided Upper 95\%/95\% TL Across all Activities 13

Table 5.3: Participant 95\% Confidence Intervals for MV, MIF, and PIF ........................................ 13

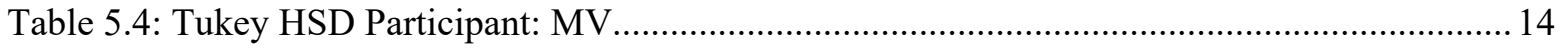

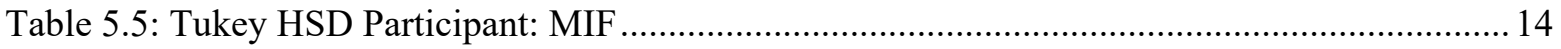

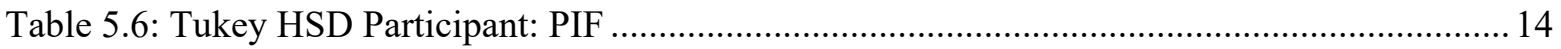

Table 5.7: Activity MV, MIF, and PIF and One-sided Upper 95\%/95\% TL Across all Activities .... 15

Table 5.8: Activity 95\% Confidence Intervals for MV, MIF, and PIF .......................................... 15

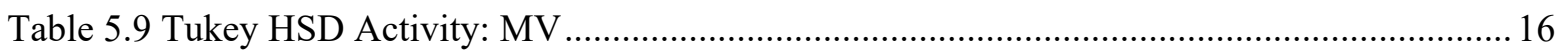

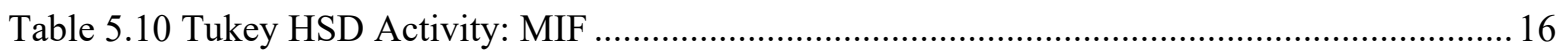

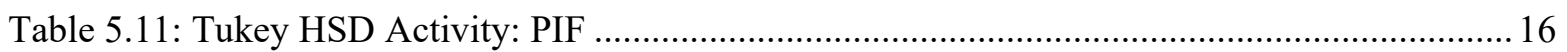

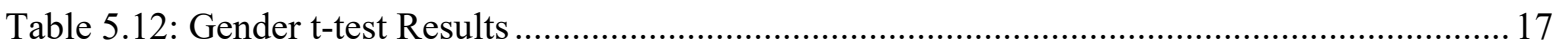




\section{Nomenclature}

\section{Abbreviations}

APF

ATD

CFR

CL

CPR

HSD

LPM

MIF

MV

$\mathrm{NIOSH}$

OSHA

PAPR

PDL

PIF

SD

STEPS

TL

LS

BMI

CI

\section{Symbols}

$\alpha$

$\bar{x}$

$\gamma$

$\mathrm{n}$
Assigned Protection Factor Aerosol Transmissible Diseases

Code of Federal Regulations

Confidence Level

Cardiopulmonary resuscitation

Honestly Significant Difference

Liters per Minute

Mean Inhalation Flow

Minute Volume

National Institute of Occupational Safety and Health

Occupational Safety and Health Administration

Powered Air Purifying Respirator

Pressure Data Logger

Peak Inhalation Flow

Standard Deviation

WVU Center for Simulation Training and Education for Patient Safety

Tolerance limit

Least Square

Body Mass Index

Confidence Interval
Statistical Significance Level

Sample Mean

Tolerance Level: Probability that at least $\mathrm{P}$ proportion is less than

number of observations 


\section{Introduction}

\subsection{General Respiratory Protection}

In general, a respirator is a protective device that covers the nose and mouth or the entire face or head to protect the user from hazardous atmospheres. There are two main types of respirators, air-purifying respirators and atmosphere-supplying respirators. An atmospheresupplying respirator provides the user with uncontaminated air from an external source, such as a tank. In contrast, an air-purifying respirator relies on an air filter element or a cartridge to capture specified airborne contaminates before the user inhales them.

Respirators are further classified into tight-fitting or loose-fitting facepiece; a tight-fitting respirator requires a continuous seal between the respirator and the user's face. Tight-fitting respirators are available in two basic types half mask, and full face. In contrast, loose-fitting respirators do not require a continuous seal with the user's face to provide protection. There are both filtering facepiece, also referred to as disposable, and reusable tight-fitting respirators.

In general, reusable tight-fitting respirators are elastomeric type respirators meaning that the facepiece is made of rubber or silicone that forms a seal with the user's face. All elastomeric respirators are equipped with an exhalation valve. Elastomeric respirators have replaceable cartridges and or filters. The type of filter or cartridges depends on the type of airborne contaminants potentially present. Cartridges are generally used to capture nonparticulate hazards, such as gases or vapors. Combination filters and cartridges can be used to provide protection against both particulates and gases or vapors.

The filtering facepiece respirator (FFR) does not require a filter cartridge because the entire respirator is the filter. Filtering facepiece respirators may be equipped with an exhalation valve. The most commonly used FFR is the NIOSH certified N95 without exhalation valve.

\subsubsection{Respirator Approvals and Regulations}

In accordance with current Occupational Safety and Health regulations, "A respirator shall be provided to each employee when such equipment is necessary to protect the health of such employee." Currently, all respirators used in the workplace must be certified by the National Institute for Occupational Safety and Health (Occupational Safety and Health 
Administration, 1998). In 1972, shortly after the enactment of the Occupational Safety and Health Act, the National Institute for Occupational Safety and Health (NIOSH) and the U.S. Bureau of Mines jointly promulgated 30 C.F.R. part 11. This regulation described specific approvable procedures and established test requirements for respirators. Since then, in the United States, all respirator approval and certification functions are now the sole responsibility of NIOSH. The current approval regulations can be found in 42 C.F.R. part 84. All NIOSH certified respirators are accompanied with a subsequent approval label. (Colton, 2012).

\subsubsection{Particulate Filter Classifications}

NIOSH also assigns class designations to particulate filters used for respiratory protection. For example, the term N95 refers to the filter classification; NIOSH certifies nine classes of filters. The letter in the designation can either be N, R or P, which corresponds to "not resistant to oil", "somewhat resistant to oil" and "strongly resistant to oil (oil proof)", respectively. The number refers to the efficiency rating of the filter. For example, an N95 respirator is at least $95 \%$ efficient at removing oil free aerosols of at least 0.3 microns in aerodynamic diameter. All filters with one of these class designations are discarded at the end of their service life; if they are a permanent part of the respirator, the entire respirator is discarded. (NIOSH, 2018)

\subsubsection{Assigned Protection Factor}

OSHA has established assigned protection factors for different types and classes of respirators. The assigned protection factor is a numerical representation of the respiratory protection level provided by that respirator or class of respirator when worn properly. For example, a half-mask air-purifying respirator that has an assigned protection factor of 10 means that "the respirator will reduce the concentration breathed in by ten times compared to the actual airborne concentration." (Colton, 2012) 


\begin{tabular}{|c|c|c|c|c|c|}
\hline Type of respirator ${ }^{1}, 2$ & Quarter mask & Half mask & k $\begin{array}{l}\text { Full } \\
\text { facepiece }\end{array}$ & $\begin{array}{l}\text { Helmet/ } \\
\text { ehood }\end{array}$ & Loose-fitting facepiece \\
\hline 1. Air-Purifying Respirator & 5 & 310 & 50 & & \\
\hline 2. Powered Air-Purifying Respirator (PAPR) & $\ldots \ldots \ldots \ldots$ & 50 & 1,000 & $425 / 1,0002$ & 25 \\
\hline $\begin{array}{l}\text { 3. Supplied-Air Respirator (SAR) or Airline Respirator } \\
\text { - Demand mode } \\
\text { - Continuous flow mode } \\
\text { - Pressure-demand or other positive-pressure mode }\end{array}$ & & $\begin{array}{l}10 \\
50 \\
50\end{array}$ & \begin{tabular}{|l}
50 \\
1,000 \\
1,000
\end{tabular} & ${ }^{4} 25 / 1,0002$ & 25 \\
\hline $\begin{array}{l}\text { 4. Self-Contained Breathing Apparatus (SCBA) } \\
\text { - Demand mode } \\
\text { - Pressure-demand or other positive-pressure mode (e.g., open/closed circuit) }\end{array}$ & & 10 & $\begin{array}{l}50 \\
10,000\end{array}$ & $\begin{array}{l}50 \\
10,000\end{array}$ & \\
\hline
\end{tabular}

${ }^{1}$ Employers may select respirators assigned for use in higher workplace concentrations of a hazardous substance for use at lower concentrations of that substance, or when required respirator use is independent of concentration.

${ }^{2}$ The assigned protection factors in Table 1 are only effective when the employer implements a continuing, effective respirator program as required by this section (29 CFR 1910.134), including training, fit testing, maintenance, and use requirements.

${ }^{3}$ This APF category includes filtering facepieces, and half masks with elastomeric facepieces.

${ }^{4}$ The employer must have evidence provided by the respirator manufacturer that testing of these respirators demonstrates performance at a level of protection of 1,000 or greater to receive an APF of 1,000. This level of performance can best be demonstrated by performing a WPF or SWPF study or equivalent testing. Absent such testing, all other PAPRs and SARs with helmets/hoods are to be treated as loose-fitting facepiece respirators, and receive an APF of 25

${ }^{5}$ These APFs do not apply to respirators used solely for escape. For escape respirators used in association with specific substances covered by $29 \mathrm{CFR} 1910$ subpart Z, employers must refer to the appropriate substance-specific standards in that subpart. Escape respirators for other IDLH atmospheres are specified by 29 CFR 1910.134 (d)(2)(ii).

Table 1.1: OSHA Assigned Protection Factors

\subsubsection{Respirator Fit-Testing}

As previously stated, all tight-fitting respirators must form a continuous seal with the users face in order to function properly. Thus, the Occupational Safety and Health Administration mandates that anyone who is required to wear a tight-fitting respirator be fit tested at least annually. Fit testing may be either quantitative or qualitative. Qualitative fit testing works by subjecting the user to a non-harmful irritant while wearing the respirator then evaluating their reaction, or lack thereof, to determine if there is any leakage. In contrast quantitative fit testing is preformed using a machine that quantitatively measure seal leakage.

\subsection{Powered Air Purifying Respirators}

A powered air-purifying respirator (PAPR) uses a battery powered blower to move air through a filter and to the user. PAPRS are also categorized into tight-fitting or loose-fitting. However, the primary focus of this research is loose-fitting PAPRs. Figure 1.1 depicts a loosefitting powered air purifying respirator.

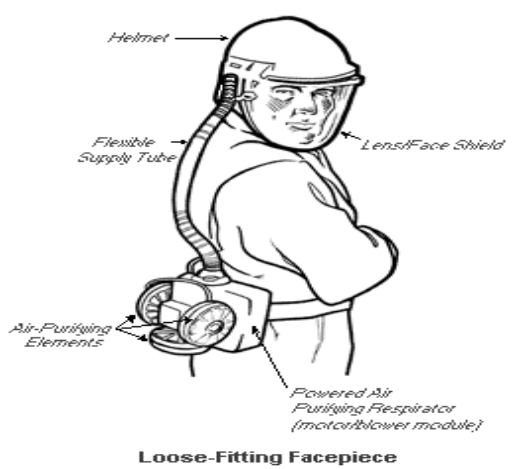

Figure 1.1 (OSHA) 


\subsection{Powered Air Purifying Respirators in Healthcare}

In accordance with current OSHA regulations, "A respirator shall be provided to each employee when such equipment is necessary to protect the health of such employee." (Occupational Safety and Health Administration, 1998). Hospitals and other healthcare environments present a variety of challenging safety and health issues. In the healthcare setting, workers may be exposed to a variety of airborne contaminates such as cleaning chemicals, hazardous drugs, and aerosol transmissible diseases.

Aerosol transmissible diseases (ATD) are diseases transmitted when infectious agents, which are suspended or present in particles or droplets, contact the mucous membranes or are inhaled. (National Institute for Occupational Safety and Health, 2020 ) Humans can produce respiratory aerosols by several means including, breathing, talking, coughing, and sneezing. It is vitally important to protect healthcare workers from exposure to any ATD that may be present in those aerosols. Filtering facepiece respirators and surgical masks are the most frequently used respiratory protection devices in the health care environment.

PAPRs are utilized in a variety of different situations in healthcare environments. PAPRs provide several distinct advantages over both elastomeric respirators and disposable respirators. Since PAPRs do not seal to the users face they are not required to be fit tested, PAPRs can also be less physiologically straining since they do not rely on the users respiratory system to move air through the filters, for this same reason PAPRs are also generally considered more comfortable. Loose fitting PAPRs provide continuous positive pressure airflow to the user, which in turn, helps the user stay cool and comfortable. (3M United States, 2018) Also, as shown in figure 1.1 PAPRs have a significantly higher assigned protection factor compared to other air purifying respirators.

\subsection{Objective}

The objective of this study is to characterize the inhalation breathing flows of healthcare workers preforming patient care activities typically preformed in an intensive care unit. Data collected will be used to determine the feasibility of lowering the minimum operational flow rate 
of loose fitting PAPRs used in the healthcare setting. Currently NIOSH regulations require the minimum operational flow of PAPRS to be at least 170 liters per minute. However, this regulation was written based on data collected from industry related work activities. Lowering the minimum operational flow rate for use in healthcare settings would be advantageous for several reasons, including reducing device weight, longer run times, and reducing manufacturing costs.

\section{Literary Review}

PAPRs are generally considered to provide a high level of respiratory protection because they create a positive pressure environment inside the hood or mask. Airborne contaminates are unlikely to naturally move from a lower pressure environment to a higher-pressure environment. However, if the user's peak inhalation flowrate exceeds the PAPRs air flow delivery rate, a negative pressure environment can be created and airborne contaminates can be drawn into the mask or hood. Thus, it is of vital importance to understand the respiratory flow characteristics of the user before any adjustments to the minimum operational flow are made. However, at current flow requirements it has been found that while high workloads can create occasional negative pressure spikes, they have minimal effect on the protection provided by the respirator. (Janssen, Anderson, Cassidy, Weber, \& Nelson, 2005)

Very limited research studies have examined the respiratory flow characteristics of health care workers. One problem attributing to the minimal research on the feasibility of lowering the minimal operational flow of PAPRs used in healthcare settings was the lack of technology to accurately record respiratory flow rates during healthcare related activities proper. The S.E.A group's pressure data logger (PDL) device solves this problem. The performance of the S.E.A pressure data logger was assessed and compared with a respiratory flow recorder. Both devices

were assessed by recording the respiratory flows of 15 subjects performing a series of simulated healthcare work activities. The assessment found that the S.E.A groups PDL produced minimal variability and would be the best choice to further investigate the respiratory flow characteristics of health care workers The recorded respiratory flows during the assessment provide the some preliminary insight into the respiratory flow characteristics of healthcare workers preforming healthcare related activities. (Zhu, et al., 2018) 
Part one of this study was "a pilot study of minimum operational flow for loose-fitting powered air-purifying respirators used in healthcare cleaning services." The study examined the breathing flow characteristics of nine health care workers to explore the feasibility of lowering the minimum operational flow rate of PAPRS used in the health care setting. The nine subjects in the study wore a S.E.A PDL while preforming cleaning and disinfecting work typically preformed in an Isolation unit. The study found that the average MV, MIF and PIF for isolation unit cleaning work was 33, 74, and 107 the respective maximum airflow rates were, 41, 97 and 145. The maximum flow rates are all lower than the required minimum operational flow rate of 170 liters per minute. (Zhu, et al., 2019)

\section{Methods}

\subsection{Participants}

Nine health care workers were recruited to participate in the study. Approval from the West Virginia University Institutional Review Board (protocol number 2007061495) was obtained prior to subject recruitment. All subjects were recruited from WVU Medicines Ruby Memorial Hospital. Before participating, all subjects reviewed and signed the "Consent Information and HIPPA Form" and completed an OSHA respirator medical questionnaire. All OSHA medical clearance questionnaires were reviewed and approved before the study began. Of the nine participants, two were respiratory therapists and seven were registered nurses. The participant's age, weight and height were $28.2 \pm 6.06$ years, $69.89 \pm 4.20$ inches and $171 \pm 40.69$ pounds (means \pm standard deviation), respectively. Table 3.1 provides individual data for each participant.

Table 3.1 Participant Physical Measurements

\begin{tabular}{ccccc}
\hline Participant \# & Sex & Age & Height & Weight \\
\hline $\mathbf{1}$ & F & 23 & 73 & 160 \\
$\mathbf{2}$ & F & 23 & 66 & 150 \\
$\mathbf{3}$ & F & 27 & 66 & 131 \\
$\mathbf{4}$ & M & 29 & 71 & 200 \\
$\mathbf{5}$ & F & 26 & 67 & 140 \\
$\mathbf{6}$ & M & 26 & 72 & 198 \\
$\mathbf{7}$ & F & 24 & 64 & 125 \\
$\mathbf{8}$ & M & 35 & 75 & 185 \\
$\mathbf{9}$ & M & 41 & 75 & 250 \\
\hline
\end{tabular}




\subsection{Instrumentation}

Inhalation and exhalation pressure were measured using the S.E.A Pressure Data Logger (PDL) This device measures and records pressure inside of a Sündstrom SR100 half mask elastomeric respirator using a small silicon adapter attached to the respirator's exhalation port (Figure 3.1). The PDL records the pressure inside the respirator at a sampling rate frequency of $50 \mathrm{~Hz}$. The PDL device is capable of sampling continuously for 8 hours. After the data is collected, the included software converts the data points into respiratory flow using a second order polynomial best fit calibration curve.

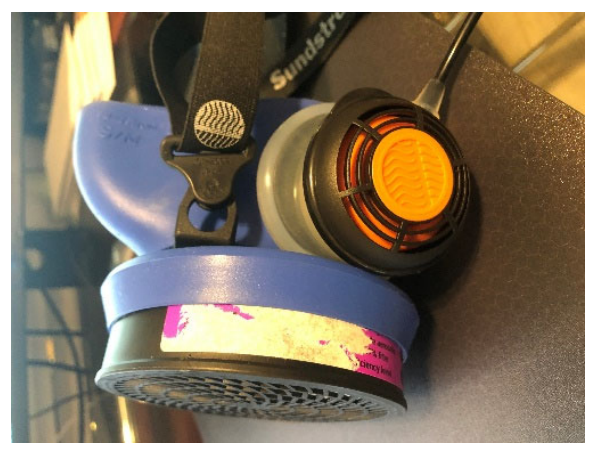

Figure 3.1 Sündstrom SR100 Silicon adapter

\subsubsection{Pressure Data Logger Calibration}

In order to accurately determine respiratory flow, the pressure recorded by the PDL must be converted to flow using four calibration constants derived from an inhalation and exhalation second order polynomial best fit calibration curve. The filter characterization setup was done by fully sealing the Sündstrom SR100 half mask elastomeric respirator to a mannikin head, a TSI Airpro Micromanometer Model AP800 (TSI, 2017), was then attached to the silicon exhalation valve adapter, shown in Figure 3.1. The mannikins air way was then connected to the laboratory vacuum line. In order to measure flow, a TSI 5000 series flow meter was connected in line with the mannikins airway.

Once the setup was completed, the vacuum was started. Utilizing the flow meter output, the airflow was increased in 10 liters per minute intervals up to 250 liters per minute. At each 10 liters per minute interval, the pressure displayed on the TSI Airpro Micromanometer was recorded. Since the laboratory vacuum line would only supply approximately 90 liters per minute, a Shop-Vac and a variable transformer device were used to produce flowrates greater than 90 liters per minute. Once all the data points were collected, the airflow was reserved, and 
the process was repeated to develop an exhalation calibration curve. The collected pressure and flow data points were input into Microsoft Excel and a graph was produced for both the inhalation and exhalation curves. Using Microsoft Excel, a $2^{\text {nd }}$ order polynomial best fit trend line was fit to the data and its corresponding $a x^{2}+b x+c$ equation was displayed for both the inhalation and exhalation data points. The a and $b$ coefficients for the inhalation curve and the exhalation curve of the polynomial equation are inputted as "Aneg", "Bneg" and "Apos" and "Bpos" respectively. (The S.E.A Group, 2015)The graphs for the exhalation and inhalation calibration curves are shown and Figure 3.2 and 3.3 respectively.

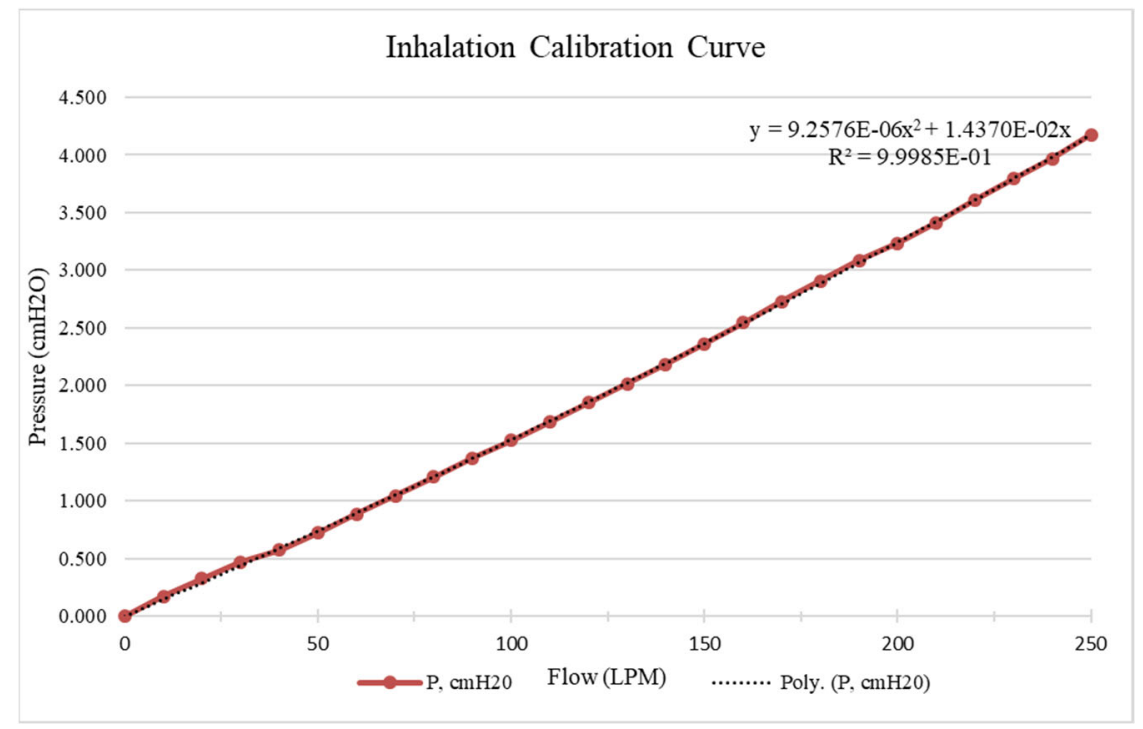

Figure 3.2 Inhalation Calibration Curve

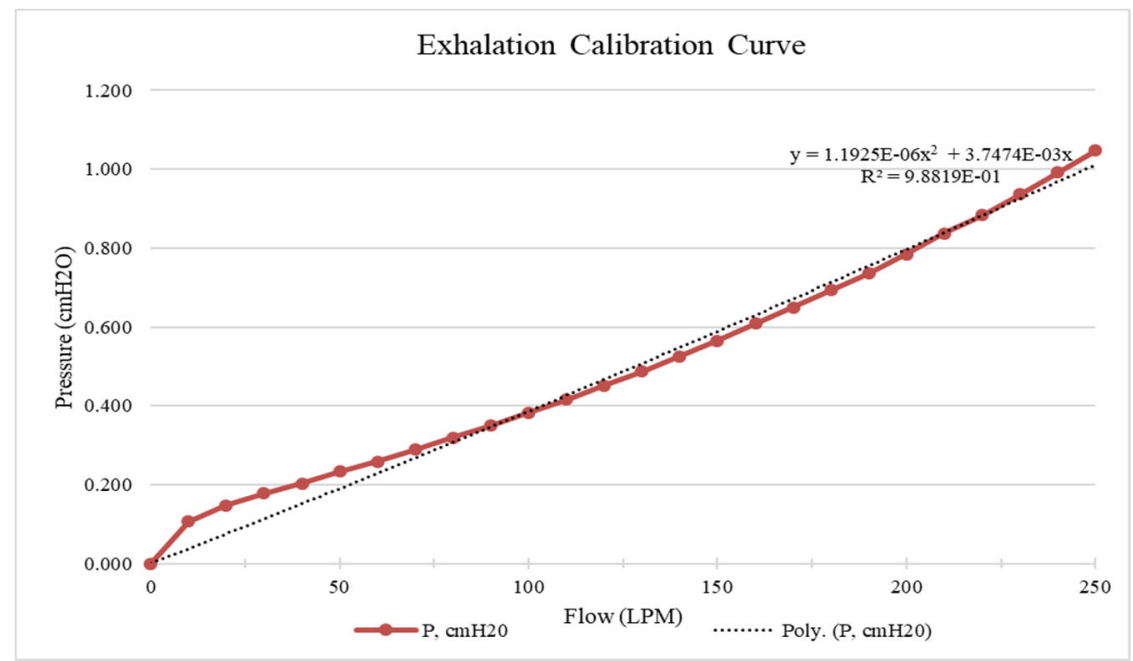

Figure 3.3 Exhalation Calibration Curve 


\subsection{Experimental Design and Procedure}

In order to best simulate a hospital environment, this study was conducted in the West Virginia University Patient Safety Simulation Center. All patient care activities were completed on a mannikin (Figure $3.4 \&$ Figure 3.5). All necessary equipment for each patient care activity was provided by the STEPs lab. This included an IV start kit, blood draw tubes, needles, tourniquet suction line, cardiac monitor, laryngoscope, endotracheal tube, bathing items (wash basin, rags, etc.), and a Bard® Foley catheter kit.

Each subject was quantitively fit tested using a TSI PortaCount (serial number: 8038102806) before they began the study. The fit testing results can be found in the appendix of this report. Each participant wore either a small/medium or medium/large Sündstrom SR100 half mask elastomeric respirator with the PDL device attached. The inspiratory flows of each participant were recorded during three randomized replications of twelve patient care activities typically preformed in an intensive care unit. The patient care activities included: changing bedding, turning and positioning the patient, patient health history review, hooking up a cardiac monitor, inserting and starting an IV, drawing blood tubes, patient passive range of motion exercises, inserting setting up and removing a foley catheter, bathing and turning the patient, performing five rounds of CPR (30 compressions 2 breaths equals one round), and inserting and removing a breathing tube.

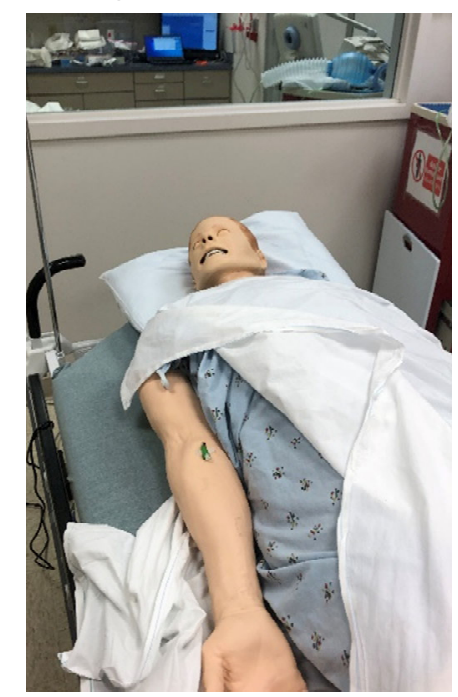

Figure 3.5: STEPs mannikin

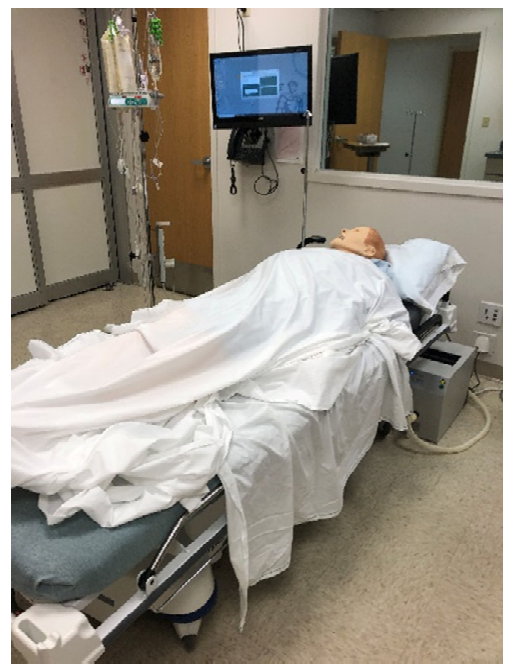

Figure 3.5: STEPs mannikin 2 
For the inspiratory flows of each activity to be analyzed separately, the participants were asked to hold their breath for five to ten seconds at the start and end of each activity. The start and stop times for each activity were also manually recorded. This allowed for a graphical indicator of the start and end time of each activity (Figure 3.6). Each participant was asked to follow standard hospital procedures and complete the activity as they normally would. Due to individual variables in speed and technique, the time required to complete the patient care activities varied by participant. It should also be noted that participants 3, 4 and 5 talked intermittently during the patient care activities, while the remaining participants were asked to not talk, unless the activity required communication E.g. patient health history.

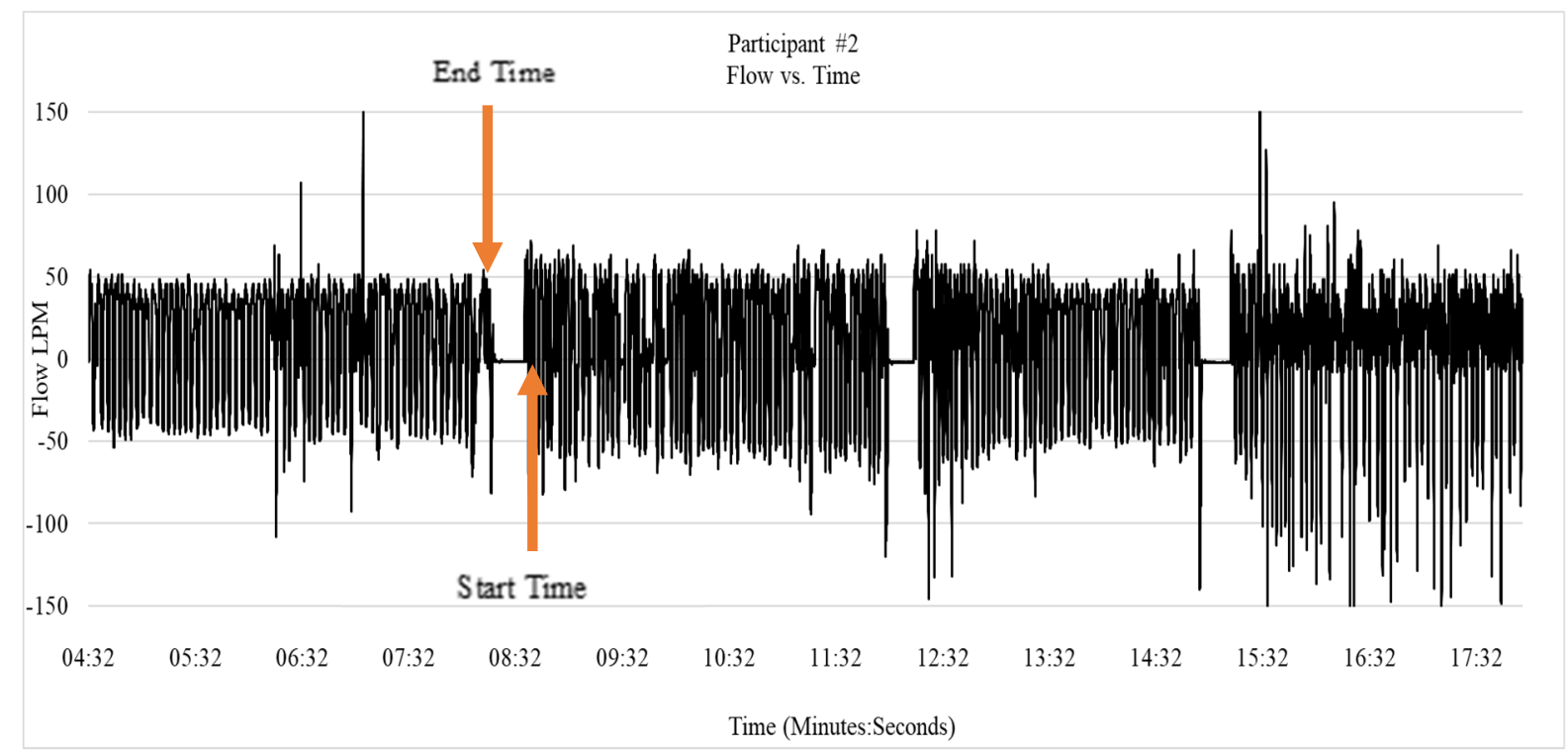

Figure 3.6: Flow vs. Time Participant \# 2

\section{Data Analysis}

Once the data was downloaded from the PDL device, the PDL software was then used to download the participants respiratory flows as a comma separated value (CSV) file. The file was then opened in Microsoft Excel and elapsed time values were added to the data. The PDL device records both positive and negative flows, however, due to the low resistance of the exhalation values, it is recommended by the manufacturer that the exhalation flows not be used for analysis. 
Thus, only the negative values created by inhalation flow through the air purifying, P100 filter were used for analysis.

The participants respiratory flow rates were graphed in 15-minute intervals. The graphs were then examined, and the recorded activity start and stop time were either confirmed or adjusted to match when the participant held their breath. The data was then filtered and separated by replication and activity, the total volume inhaled, $50^{\text {th }}$ percentile inhalation flow, $75^{\text {th }}$ percentile inhalation flow, minute volume (MV), mean inhalation flow (MIF), and peak inhalation flow (PIF) were calculated for each activity replication. Minute volume was calculated by dividing the total volume inhaled by the elapsed time. Mean inhalation flow was calculated by taking the average of all the inhalation flow for the activity. The peak inhalation flow was calculated by taking the average of the inhalation flows greater than the $75^{\text {th }}$ percentile to equate for the top $25 \%$ of inhalation flow values. In order to report with $95 \%$ confidence that the $95 \%$ of flows are less than a specific value, upper tolerance limits were calculated for MV, MIF, and PIF. across all participants for each activity. The following formula (Figure 4.1) was used to calculate upper tolerance limits. Where the $\mathrm{K}$ factor is a pre-determined, statistical value such that the probability is $\gamma$ that at least a proportion $\mathrm{P}$ of the distribution will be less than $\overline{\mathrm{x}}+k$, where $\overline{\mathrm{x}}$ and $\mathrm{s}$ are estimates of the mean and the standard deviation. (National Bureau of Standards , 1963)

$$
\mathrm{TL}_{95,95}=\overline{\mathrm{x}}+\mathrm{K}_{\gamma, \mathrm{P}, \mathrm{n}} * \mathrm{~S}
$$

Figure 4.1: Tolerance Limit Equation

\subsection{Statistical Analysis}

All statistical analysis was performed using JMP Pro 15. Each participant's, MV, MIF, and PIF for each activity replication were used for the analysis. An analysis of variance was conducted to compare the effect of participant and activity on MV, MIF, and PIF. The confidence intervals for each activity and participant are also reported. If a significant difference was determined through the analysis of variance results, then a post hoc analysis of the effect of participant and activity on MV, MIF, and PIF was performed through the Tukey's honestly significant difference test. The average MV, MIF, and PIF for all participants both male and 
females was calculated, and three two sample t-tests were performed to determine if gender had a significant effect.

\section{Results and Discussion}

The results of this study are summarized in the following tables. Activities 1 through 12 are defined as; insert setup and remove a foley catheter, changing bedding, inserting and removing a breathing tube, patient health history review, hooking up a cardiac monitor, drawing blood tubes, passive range of motion exercises, turning and positioning the patient, suctioning the patient, preforming CPR, inserting and starting an IV, and bathing and turning the patient, respectively (Table 5.1). Each participant's MV, MIF and PIF and upper tolerance limits across all activities are shown in Table 5.2. The upper tolerance limits indicate with $95 \%$ confidence, that $95 \%$ of the data is below the indicated value. Also, the confidence intervals for each participant are reported in Table 5.3.

Table 5.1: Patient Care Activities Summary

\begin{tabular}{ll}
\hline Activity 1 & Insert Setup and Remove a Foley Catheter \\
Activity 2 & Changing Bedding \\
Activity 3 & Inserting and Removing A Breathing Tube \\
Activity 4 & Patient Health History Review \\
Activity 5 & Hooking Up A Cardiac Monitor \\
Activity 6 & Drawing Blood Tubes \\
Activity 7 & Passive Range of Motion Exercises \\
Activity 8 & Turning and Positioning the Patient \\
Activity 9 & Suctioning the Patient \\
Activity 10 & Preforming CPR \\
Activity 11 & Inserting and Starting An IV \\
Activity 12 & Bathing and Turning the Patient \\
\hline
\end{tabular}


Table 5.2: Participant MV, MIF, and PIF and One-sided Upper 95\%/95\% TL Across all Activities

\begin{tabular}{lcccccc}
\hline & MV & MIF & PIF & MV & MIF & PIF \\
\cline { 2 - 7 } & Mean \pm Sd & Mean \pm Sd & Mean \pm Sd & $\begin{array}{c}\text { TL95,95 } \\
\text { K=2.736 }\end{array}$ & $\begin{array}{c}\text { TL95,95 } \\
\text { K=2.736 }\end{array}$ & $\begin{array}{c}\text { TL95,95 } \\
\text { K=2.736 }\end{array}$ \\
\hline Participant 1 & $23.1 \pm 4.0$ & $59.8 \pm 10.6$ & $96.5 \pm 21.4$ & 34.1 & 88.8 & 154.9 \\
Participant 2 & $16.3 \pm 2.3$ & $40.6 \pm 5.0$ & $65.0 \pm 13.0$ & 22.5 & 54.2 & 100.6 \\
Participant 3 & $13.7 \pm 2.1$ & $43.2 \pm 8.3$ & $77.9 \pm 16.5$ & 19.4 & 66.0 & 123.0 \\
Participant 4 & $20.3 \pm 5.0$ & $47.8 \pm 7.5$ & $91.2 \pm 14.9$ & 34.0 & 68.3 & 132.0 \\
Participant 5 & $14.8 \pm 1.8$ & $32.4 \pm 4.7$ & $69.2 \pm 6.9$ & 19.7 & 45.4 & 88.2 \\
Participant 6 & $24.2 \pm 2.9$ & $54.0 \pm 6.9$ & $89.7 \pm 15.9$ & 32.2 & 72.9 & 133.2 \\
Participant 7 & $20.4 \pm 3.3$ & $52.6 \pm 6.1$ & $84.1 \pm 16.7$ & 29.5 & 69.1 & 129.9 \\
Participant 8 & $23.2 \pm 3.9$ & $55.9 \pm 6.7$ & $87.9 \pm 15.6$ & 33.9 & 74.4 & 130.6 \\
Participant 9 & $28.5 \pm 4.7$ & $63.9 \pm 8.6$ & $114.4 \pm 16.0$ & 41.5 & 87.3 & 158.2 \\
\hline
\end{tabular}

Table 5.3: Participant 95\% Confidence Intervals for MV, MIF, and PIF

\begin{tabular}{lccc}
\hline & MV & MIF & PIF \\
\cline { 2 - 4 } & $\mathbf{9 5}$ \% CI & $\mathbf{9 5}$ \% CI & 95 \% CI \\
\hline Participant 1 & {$[21.8,24.5]$} & {$[56.2,63.4]$} & {$[89.2,103.7]$} \\
Participant 2 & {$[15.5,17.1]$} & {$[38.9,42.2]$} & {$[60.6,69.4]$} \\
Participant 3 & {$[13.0,14.4]$} & {$[40.4,46.0]$} & {$[72.4,83.5]$} \\
Participant 4 & {$[18.6,22.0]$} & {$[45.3,50.3]$} & {$[86.2,96.2]$} \\
Participant 5 & {$[14.1,15.4]$} & {$[30.8,34.0]$} & {$[66.9,71.6]$} \\
Participant 6 & {$[23.3,25.2]$} & {$[51.7,56.3]$} & {$[84.3,95.1]$} \\
Participant 7 & {$[19.2,21.5]$} & {$[50.5,54.6]$} & {$[78.5,89.8]$} \\
Participant 8 & {$[21.8,24.5]$} & {$[53.6,58.2]$} & {$[82.6,93.2]$} \\
Participant 9 & {$[26.9,30.1]$} & {$[61.0,66.8]$} & {$[108.9,119.8]$} \\
\hline
\end{tabular}

An analysis of variance revealed that at a significance level of $\alpha=0.05$, participant does have a significant effect on MV, MIF, P.I.F. The following tables summarize the results of a post hoc Tukey HSD tests performed on the effect of participant (Table 5.4, Table 5.5, and Table 5.6). 
Table 5.4: Tukey HSD Participant: MV

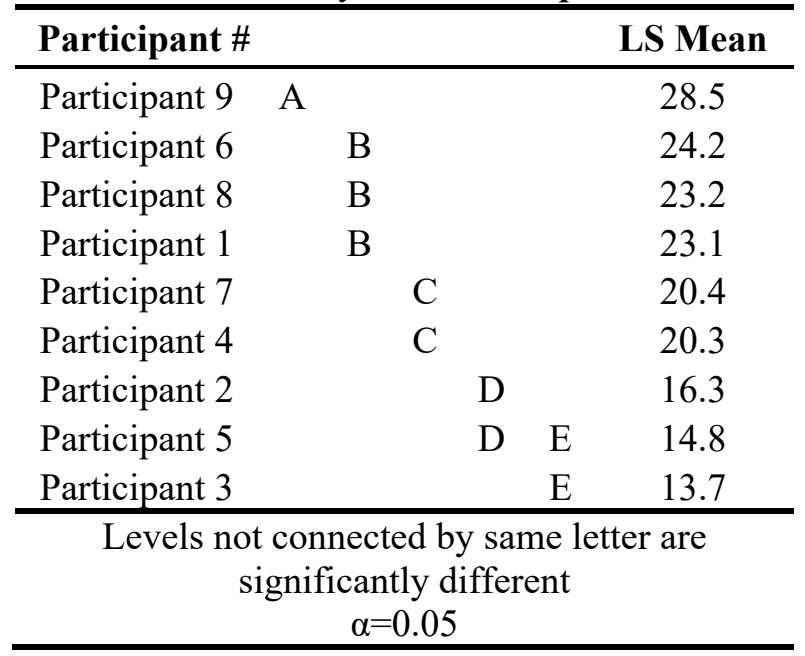

Table 5.5: Tukey HSD Participant: MIF

\begin{tabular}{|c|c|c|c|c|c|c|}
\hline Participant \# & & & & & & LS Mean \\
\hline Participant 9 & A & & & & & 63.9 \\
\hline Participant 1 & A B & & & & & 59.8 \\
\hline Participant 8 & B & $\mathrm{C}$ & & & & 55.9 \\
\hline Participant 6 & & $\mathrm{C}$ & & & & 54.0 \\
\hline Participant 7 & & $\mathrm{C}$ & $\mathrm{D}$ & & & 52.6 \\
\hline Participant 4 & & & $\mathrm{D}$ & $\mathrm{E}$ & & 47.8 \\
\hline Participant 3 & & & & $\mathrm{E}$ & $\mathrm{F}$ & 43.2 \\
\hline Participant 2 & & & & & $\mathrm{~F}$ & 40.6 \\
\hline Participant 5 & & & & & $\mathrm{G}$ & 32.4 \\
\hline \multicolumn{7}{|c|}{$\begin{array}{l}\text { Levels not connected by same letter are significantly } \\
\text { different } \\
\alpha=0.05 \\
\end{array}$} \\
\hline
\end{tabular}

Table 5.6: Tukey HSD Participant: PIF

\begin{tabular}{|c|c|c|c|c|c|c|}
\hline Participant \# & & & & & & LS Mean \\
\hline Participant 9 & & & & & & 114.4 \\
\hline Participant 1 & B & & & & & 96.5 \\
\hline Participant 4 & $\mathrm{~B}$ & $\mathrm{C}$ & & & & 91.2 \\
\hline Participant 6 & B & $\mathrm{C}$ & & & & 89.7 \\
\hline Participant 8 & $\mathrm{~B}$ & $\mathrm{C}$ & $\mathrm{D}$ & & & 87.9 \\
\hline Participant 7 & & $\mathrm{C}$ & $\mathrm{D}$ & & & 84.1 \\
\hline Participant 3 & & & $\mathrm{D}$ & $\mathrm{E}$ & & 77.9 \\
\hline Participant 5 & & & & $\mathrm{E}$ & $\mathrm{F}$ & 69.2 \\
\hline Participant 2 & & & & & $\mathrm{~F}$ & 65.0 \\
\hline \multicolumn{7}{|c|}{$\begin{array}{l}\text { Levels not connected by same letter are significantly } \\
\text { different } \\
\alpha=0.05\end{array}$} \\
\hline
\end{tabular}

The average MV, MIF, and PIF across all participants for each activity was calculated and an analysis of variance was performed. The average values for each activity are summarized in Table 5.7 the upper $95-95 \%$ tolerance limits are also recorded. The $95 \%$ confidence intervals for each activity are shown in Table 5.8. 
Table 5.7: Activity MV, MIF, and PIF and One-sided Upper 95\%/95\% TL Across all Activities

\begin{tabular}{ccccccc}
\hline & MV & MIF & PIF & MV & MIF & PIF \\
\cline { 2 - 6 } & Mean \pm Sd & Mean \pm Sd & Mean \pm Sd & $\begin{array}{r}\text { TL95,95 } \\
\text { K=3.031 }\end{array}$ & $\begin{array}{r}\text { TL95,95 } \\
\text { K=3.031 }\end{array}$ & $\begin{array}{r}\text { TL95,95 } \\
\text { K=3.031 }\end{array}$ \\
\hline Activity 1 & $19.0 \pm 5.2$ & $46.6 \pm 10.8$ & $76.3 \pm 17.5$ & 34.8 & 79.3 & 129.2 \\
Activity 2 & $22.6 \pm 5.7$ & $53.9 \pm 11.1$ & $90.5 \pm 16.4$ & 39.8 & 87.6 & 140.1 \\
Activity 3 & $19.5 \pm 4.8$ & $47.8 \pm 10.2$ & $81.0 \pm 16.0$ & 34.2 & 78.6 & 129.5 \\
Activity 4 & $15.9 \pm 3.2$ & $48.7 \pm 11.6$ & $110.3 \pm 26.9$ & 25.6 & 83.9 & 191.7 \\
Activity 5 & $19.6 \pm 4.7$ & $48.0 \pm 9.9$ & $80.1 \pm 16.5$ & 33.7 & 77.9 & 130.2 \\
Activity 6 & $17.8 \pm 4.0$ & $43.4 \pm 8.6$ & $73.4 \pm 12.8$ & 29.9 & 69.4 & 112.2 \\
Activity 7 & $20.3 \pm 5.8$ & $49.5 \pm 12.0$ & $81.2 \pm 18.1$ & 37.9 & 85.8 & 136.2 \\
Activity 8 & $23.9 \pm 7.1$ & $52.8 \pm 15.3$ & $92.8 \pm 20.8$ & 45.5 & 99.1 & 155.9 \\
Activity 9 & $20.1 \pm 5.2$ & $48.8 \pm 11.7$ & $81.3 \pm 14.7$ & 35.8 & 84.2 & 125.9 \\
Activity 10 & $25.4 \pm 5.2$ & $59.2 \pm 10.4$ & $102.6 \pm 18.8$ & 41.3 & 90.7 & 159.5 \\
Activity 1 1 & $20.0 \pm 5.8$ & $49.2 \pm 12.8$ & $80.0 \pm 18.9$ & 37.6 & 88.0 & 137.2 \\
Activity 12 & $21.8 \pm 5.6$ & $52.1 \pm 11.7$ & $85.1 \pm 18.2$ & 38.7 & 87.7 & 140.2 \\
\hline
\end{tabular}

Table 5.8: Activity 95\% Confidence Intervals for MV, MIF, and PIF

\begin{tabular}{cccc}
\hline & MV & MIF & PIF \\
\cline { 2 - 4 } & 95 \% CI & 95 \% CI & 95 \% CI \\
\hline Activity 1 & {$[17.0,21.1]$} & {$[42.4,50.9]$} & {$[69.4,83.2]$} \\
Activity 2 & {$[20.4,24.8]$} & {$[49.5,58.3]$} & {$[84.0,97.0]$} \\
Activity 3 & {$[17.6,21.4]$} & {$[43.8,51.8]$} & {$[74.6,87.3]$} \\
Activity 4 & {$[14.6,17.2]$} & {$[44.1,53.3]$} & {$[99.7,120.9]$} \\
Activity 5 & {$[17.7,21.4]$} & {$[44.1,51.9]$} & {$[73.5,86.6]$} \\
Activity 6 & {$[16.2,19.4]$} & {$[40.0,46.8]$} & {$[68.4,78.5]$} \\
Activity 7 & {$[18.0,22.6]$} & {$[44.7,54.2]$} & {$[74.1,88.4]$} \\
Activity 8 & {$[21.1,26.7]$} & {$[46.8,58.9]$} & {$[84.5,101.0]$} \\
Activity 9 & {$[18.1,22.2]$} & {$[44.2,53.5]$} & {$[75.5,87.1]$} \\
Activity 10 & {$[23.4,27.5]$} & {$[55.1,63.3]$} & {$[95.1,110.0]$} \\
Activity 11 & {$[17.7,22.3]$} & {$[44.1,54.2]$} & {$[72.6,87.5]$} \\
Activity 12 & {$[19.6,24.0]$} & {$[47.5,56.8]$} & {$[77.9,92.3]$} \\
\hline
\end{tabular}

The analysis of variance revealed activity does have a significant effect on MV, MIF, and PIF. Post hoc Tukey tests revealed that some activities did not have a significant effect when compared to others. The results of the post hoc Tukey tests are summarized below in Table 5.9, Table 5.10, and Table 5.11. It maybe intuitive to conclude that activity 10, preforming C.P.R., would be significantly different from the other activities since it has the highest MV and MIF. 
However, the Tukey tests revealed that MV for activity 10 was not significantly different from activity 8,2 , or 12 . Also MIF for activity 10 was not significantly different from activity $2,7,8$, 11,12 . It should also be noted that the upper $95 \% / 95 \%$ tolerance limit for the PIF of activity 4 , reviewing patient health history was $192 \mathrm{~L} / \mathrm{min}$. This can most likely be attributed to the effect of speech on peak inspiratory flows.

Table 5.9 Tukey HSD Activity: $M V$

\begin{tabular}{|c|c|c|c|c|c|c|}
\hline Activity \# & & & & & & $\begin{array}{c}\text { LS } \\
\text { Mean }\end{array}$ \\
\hline Activity 10 & A & & & & & 25.4 \\
\hline Activity 8 & A & B & & & & 23.9 \\
\hline Activity 2 & A & B & $\mathrm{C}$ & & & 22.6 \\
\hline Activity 12 & A & B & $\mathrm{C}$ & D & & 21.8 \\
\hline Activity 7 & & B & $\mathrm{C}$ & $\mathrm{D}$ & $\mathrm{E}$ & 20.3 \\
\hline Activity 9 & & B & $\mathrm{C}$ & D & $\mathrm{E}$ & 20.1 \\
\hline Activity 11 & & B & $\mathrm{C}$ & $\mathrm{D}$ & $\mathrm{E}$ & 20.0 \\
\hline Activity 5 & & B & $\mathrm{C}$ & $\mathrm{D}$ & E & 19.6 \\
\hline Activity 3 & & B & $\mathrm{C}$ & D & $\mathrm{E}$ & 19.5 \\
\hline Activity 1 & & & $\mathrm{C}$ & $\mathrm{D}$ & $\mathrm{E}$ & 19.0 \\
\hline Activity 6 & & & & $\mathrm{D}$ & E & 17.8 \\
\hline Activity 4 & & & & & $\mathrm{E}$ & 15.9 \\
\hline \multicolumn{7}{|c|}{$\begin{array}{l}\text { Levels not connected by same letter are } \\
\text { significantly different } \\
\alpha=0.05\end{array}$} \\
\hline
\end{tabular}

Table 5.10 Tukey HSD Activity: MIF

\begin{tabular}{ccccc}
\hline Activity \# & & & & $\begin{array}{c}\text { LS } \\
\text { Mean }\end{array}$ \\
\hline Activity 10 & A & & & 59.2 \\
Activity 2 & A & B & & 53.9 \\
Activity 8 & A & B & C & 52.8 \\
Activity 12 & A & B & C & 52.1 \\
Activity 7 & A & B & C & 49.5 \\
Activity 11 & A & B & C & 49.2 \\
Activity 9 & & B & C & 48.8 \\
Activity 4 & & B & C & 48.7 \\
Activity 5 & & B & C & 48.0 \\
Activity 3 & & B & C & 47.8 \\
Activity 1 & & B & C & 46.6 \\
Activity 6 & & & C & 43.4 \\
\hline
\end{tabular}

Levels not connected by same letter are significantly different $\alpha=0.05$

Table 5.11: Tukey HSD Activity: PIF

\begin{tabular}{ccccccc}
\hline Activity \# & & & & & & LS Mean \\
\hline Activity 4 & A & & & & & 110.3 \\
Activity 10 & A & B & & & & 102.6 \\
Activity 8 & & B & C & & & 92.8 \\
Activity 2 & & B & C & D & & 90.5 \\
Activity 12 & & C & D & E & 85.1 \\
Activity 9 & & C & D & E & 81.3 \\
Activity 7 & & C & D & E & 81.2 \\
Activity 3 & & C & D & E & 81.0 \\
Activity 5 & & C & D & E & 80.1 \\
Activity 11 & & C & D & E & 80.0 \\
Activity 1 & & & D & E & 76.3 \\
Activity 6 & & & E & 73.4 \\
\hline Levels not connected by same letter are significantly & different & & \\
\multicolumn{7}{c}{$\alpha=0.05$} \\
\hline
\end{tabular}


Three two sample t-tests were performed on MV, MIF and PIF by gender and found that gender also has a significant effect. The t-test results are summarized below in Table 5.12

Table 5.12: Gender t-test Results

\begin{tabular}{|c|c|c|c|c|c|}
\hline \multicolumn{2}{|c|}{ MV: M-F t-test Results } & \multicolumn{2}{|c|}{ MIF: M-F t-test Results } & \multicolumn{2}{|c|}{ PIF: M-F t-test Results } \\
\hline Male $($ Mean \pm SD) & $24.1 \pm 5.1$ & Male $($ Mean \pm SD $)$ & $55.4 \pm 9.4$ & Male $($ Mean \pm SD) & $95.8 \pm 18.9$ \\
\hline Female (Mean \pm SD) & $17.7 \pm 4.5$ & Female (Mean \pm SD) & $45.8 \pm 12.0$ & Female $($ Mean \pm SD) & $77.8 \pm 18.3$ \\
\hline Confidence Level & 0.95 & Confidence Level & 0.95 & Confidence Level & 0.95 \\
\hline Prob $>\mathrm{t}$ & $<.0001$ & Prob $>\mathrm{t}$ & $<.0001$ & Prob $>t$ & $<.0001$ \\
\hline
\end{tabular}

Additional study results such as the $75^{\text {th }}, 50^{\text {th }}$ percentile, activity times, and the total volume inhaled are reported in the appendix of this report.

\section{Conclusions and Limitations}

A significant limitation of this study was the relatively small sample size of nine participants. Also, this study did not include any physicians. Physicians would be performing significantly different patient care activities. Another factor that should be considered is that only three participants talked during the patient care activities, it can be inferred that in an actual health care setting communication will be more frequent. Multiple studies have concluded that speech significantly increases peak inhalation flow, thus it is imperative that the effect of speech and non-speech conditions be examined further. It is also important to consider all physical attributes of the subjects, such as weight, height and BMI. Further analysis will be needed to include these effects.

The objective of this study was to characterize the breathing flow rates of health care workers preforming patient care activities, to determine the feasibility of lowering the required minimum operational flow rate of PAPRs. The results of this study confirmed that, breathing flow characteristics are affected by individual, gender, and type of activity. 
The main variable to consider, for assessing the feasibility of lowering the minimum operational flow rates of PAPRs is peak inhalation flow. Suppose the user's peak inhalation flow rate exceeds the PAPRs airflow delivery rate. In that case, a negative pressure environment can be created, and airborne contaminants can be drawn into the mask or hood. This research demonstrated that the peak inhalation flows of certain patient care activities were significantly higher than others. Preforming CPR and patient health history review had the highest peak inhalation flows, $102.6 \pm 18.8,110.3 \pm 26.9$, respectively. The high peak inhalation flow values for preforming CPR can be attributed to the high physiological demand of the activity.

In contrast, the high peak inhalation flow for reviewing the patient health history can be attributed to the effect of speech on inspiratory flow. It is well documented that speech significantly increases inspiratory flows. Nevertheless, future research should examine the effect of different speech variables such as amplitude, intensity, and duration. Also, additional research is needed regarding the duration of peak inspiratory flow spikes. For peak inhalation flow to affect the PAPRs protection level, the peak inhalation flow must exceed the PAPRS airflow delivery rate plus the dead volume inside the facepiece, hood, or helmet. So, the time duration of peak inspiratory flow spikes is vitally important.

With such a small sample size and wide range of peak inspiratory flows, further research is needed. This study indicated that the peak inhalation flow for certain activities was not significantly different from other activities. Thus, to simplify future research, certain activities could be omitted. The activities may be limited to reviewing the patients' health history, preforming CPR, bathing and turning the patient, changing the bedding, and inserting and removing a foley catheter. The participants physical parameters are also important to consider for future research, the participant with the highest MV, PIF, and MIF also had the highest weight. To incorporate the highest inspiratory flows into future research, physical conditioning should be considered when selecting participants. Future subjects should be selected from a wide range of age, weight, body mass index, and levels of physical fitness if possible.

Due to the small sampling size, variability across participants, and the need for additional analysis the feasibility of lowering the minimum operational flow of PAPR remains inconclusive. However, these findings, combined with previous studies, provide crucial insight into healthcare workers' respiratory flow characteristics. 


\section{References}

3M United States. (2018, August 21). Using PAPRs in Clinical and Healthcare Settings. Retrieved from 3M Science Applied to Life: https://workersafety.3m.com/using-paprsclinical-healthcare-settings/

Colton, C. E. (2012). Respiratory Protection. In B. A. Plog, \& P. J. Quinlan, Fundamentals of Industrial Hygiene (6 ed., pp. 649-685). Itasca, Illinois, United States of America : National Safety Council .

Janssen, L. L., Anderson, N. J., Cassidy, P. E., Weber, R. A., \& Nelson, T. J. (2005). Interpretation of Inhalation Airflow Measurements for Respirator Design and Testing . Journal of the Internation Society of Respiratory Protection, 112.

Munnis, S. J. (2019). Evaluating the Consistency of a Breathing Flow Recording Device Across Different Elastomeric Half-Mask Respirators. Morgantown : WVU Graduate Theses, Dissertations and Problem Reports .

National Bureau of Standards . (1963). Experimental Statistics . In M. G. Natrella, Experimental Statistics .

National Institute for Occupational Safety and Health. (2020 , May 5). Healthcare Respiratory Protection Resources. Retrieved from Centers for Disease Control and Prevention : https://www.cdc.gov/niosh/npptl/hospresptoolkit/policies.html

NIOSH. (2018). A Guide to Air-Purifying Respirators. Retrieved from https://www.cdc.gov/niosh/docs/2018-176/pdfs/2018-176.pdf

Occupational Safety and Health Administration. (1998, January 8). Standard Number: 1910.134. Occupational Safety and Health Standards.

Occupational Safety and Health Administration. (n.d.). OSHA Technical Manual . Retrieved from Respiratory Protection:

https://www.osha.gov/dts/osta/otm/otm_viii/otm_viii_2.html 
Roberts, V. (2014). To PAPR or not to PAPR? Canadian Journal of Respiratory Therapy, 50(3), 87-90. Retrieved from https://www.ncbi.nlm.nih.gov/pmc/articles/PMC4456839/pdf/cjrt50-87.pdf

The S.E.A Group. (2015). Pressure Data Logger PDL Users Manual.

TSI. (2017). AirPro Micormanometer. Retrieved from TSI Understnading Accelerated .

Zhu, J., He, X., Bergman, M. S., Guffey, S., Nimbarte , A. D., \& Zhuang , Z. (2019). A pilot study of minimum operational flow for loose-fitting powered. Journal of Occupational and Enviornmental Hygiene, 440-445.

Zhu, J., He, X., Guffey, S., Bergman, M. S., Lee, E. G., \& Zhuang, Z. (2018). Assesment of Two Personal Breathing Recording Devices in a Simulated Healthcare Environment. Journal of Internation Society for Respiratory Protection, 98-111. 


\section{Appendix:}

Appendix A: Additional Study Results

Appendix B: Additional Respiratory Flow Graphs

Appendix B: Participant Fit Test Results 


\section{Appendix A: Additional Study Results:}

Participant Summary 1 (Across All Activites)

Average MIF:

$-59.81$

SD Mif

Average 50th Percentile:

50th Percentile SD:

Average 75th Percentile:

75th Percentile SD:

Average Minute Volume:

Minute Volume SD

Average Activity Time

Average Inhalation time:

Average Volume Inhalaed:

Total Volume Inhaled:

Total Time Sampled:
10.60

$-60.63$

17.02

$-79.91$

16.33

23.12

4.01

$02: 26$

$00: 57$

$-56.06$

$-2018.32$

1:27:50

Participant 2 Summary (Across All Activites)

Average MIF:

$-40.55$

SD Mif

4.99

Average 50th Percentile:

$-45.61$

50th Percentile SD:

5.05

Average 75th Percentile:

$-55.06$

75th Percentile SD:

8.19

Average Minute Volume:

16.31

Minute Volume SD

2.26

Average Activity Time

03:03

Average Inhalation time:

01:15

Average Volume Inhalaed:

$-49.58$

Total Volume Inhaled:

$-1784.90$

Total Time Sampled:

1:49:42

Participant Information:

Participan 1

Age:

23

Sex: $\quad F$

Height: $\quad 73$

Weight: $\quad 160$
Participant Information:

Participan 2

Age:

23

Sex: $\quad F$

Height: $\quad 66$

Weight:

131 
Participant 3 Summary (Across All Activites)

Average MIF:

SD Mif

Average 50th Percentile:

50th Percentile SD:

Average 75th Percentile:

75th Percentile SD:

Average Minute Volume:

Minute Volume SD

Average Activity Time

Average Inhalation time:

Average Volume Inhalaed:

Total Volume Inhaled:

Total Time Sampled:
$-43.18$

8.34

$-44.33$

8.74

$-58.96$

13.59

13.72

2.08

02:27

$00: 50$

$-34.24$

$-1232.52$

$1: 28: 27$

Participant 4 Summary (Across All Activites)

Average MIF:

$-47.81$

7.48

SD Mif

$-47.11$

Average 50th Percentile:

50th Percentile SD:

10.70

$-70.91$

11.08

75th Percentile SD:

20.27

Average Minute Volume:

5.00

Minute Volume SD

02:14

Average Activity Time

$00: 56$

Average Inhalation time:

$-43.87$

Average Volume Inhalaed:

$-1579.23$

Total Volume Inhaled:

1:20:21

Participant Information:

Participant \#: $\quad 3$

Age: $\quad 27$

Sex: $F$

Height: $\quad 66$

Weight: $\quad 131$

Total Time Sampled:

Participant Information:

Participan 4

Age: $\quad 29$

Sex: $\quad M$

Height: $\quad 71$

Weight: $\quad 200$ 


$\begin{array}{lrlr}\text { Participant 5 Summary (Across All Activites) } & \text { Participant } & \text { Information } \\ \text { Average MIF: } & -32.41 & \text { Participan } & 5 \\ \text { SD Mif } & 4.75 & \text { Age: } & 26 \\ \text { Average 50th Percentile: } & -29.92 & \text { Sex: } & \text { F } \\ \text { 50th Percentile SD: } & 9.14 & \text { Height: } & 67 \\ \text { Average 75th Percentile: } & -51.51 & \text { Weight: } & 140 \\ \text { 75th Percentile SD: } & 6.42 & & \\ \text { Average Minute Volume: } & 14.76 & & \\ \text { Minute Volume SD } & 1.82 & & \\ \text { Average Activity Time } & 02: 42 & & \\ \text { Average Inhalation time: } & 01: 15 & & \\ \text { Average Volume Inhalaed: } & -39.64 & & \\ \text { Total Volume Inhaled: } & -1426.90 & & \\ \text { Total Time Sampled: } & 1: 36: 55 & & \end{array}$

Participant 6 Summary (Across All Activites)

Participant Information:

Average MIF:

$-54.00$

Participan 6

SD Mif

6.90

Average 50th Percentile: $\quad-57.47$

50th Percentile SD: $\quad 7.09$

Average 75th Percentile: $\quad-73.98$

75th Percentile SD: $\quad 10.74$

Average Minute Volume: $\quad 24.25$

Minute Volume SD 2.91

Average Activity Time $\quad 02: 10$

Average Inhalation time: $\quad 01: 01$

Average Volume Inhalaed: $\quad-52.92$

Total Volume Inhaled: $\quad-1905.02$

Total Time Sampled: $\quad$ 1:17:47 


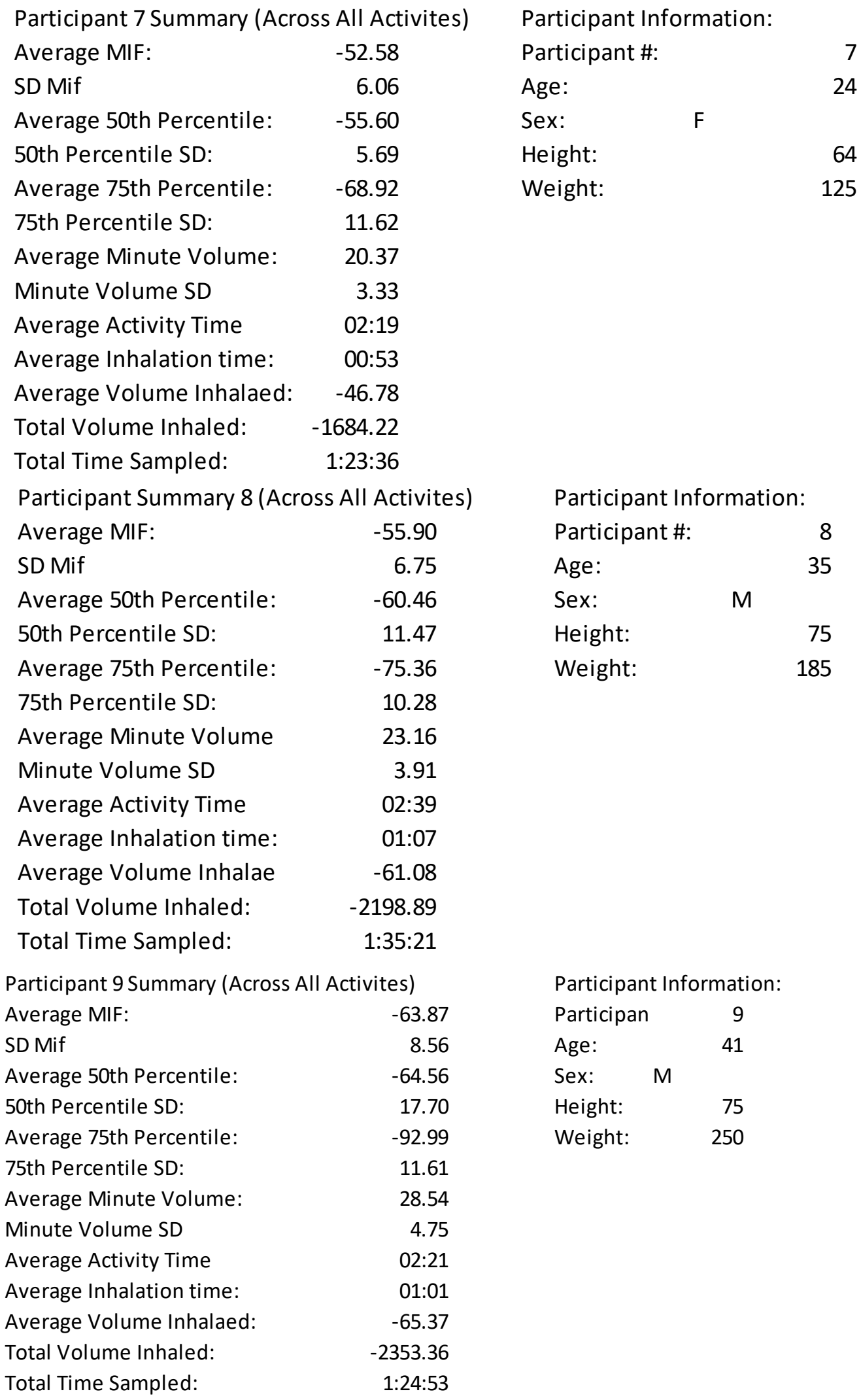




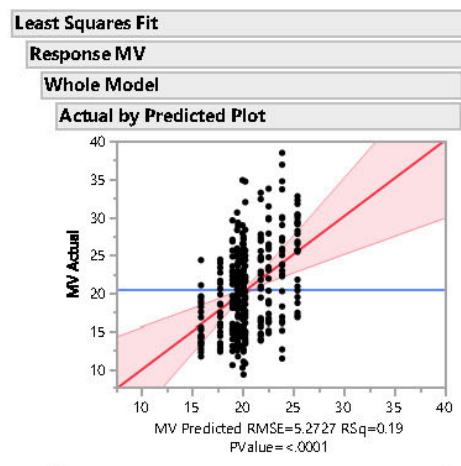

Effect Tests

Activity

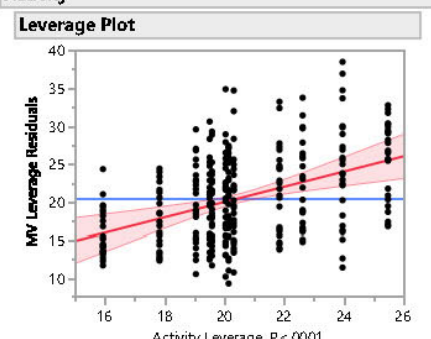

LSMeans Differences Tukey HSD

$\begin{array}{rrrrrrr}\text { Source } & \text { Nparm } & \text { DF } & \begin{array}{r}\text { Sum of } \\ \text { Squares }\end{array} & \text { F Ratio } & \text { Prob }>\text { F } \\ \text { Activity } & 11 & 11 & 2030.7143 & 6.6404 & <.0001 *\end{array}$

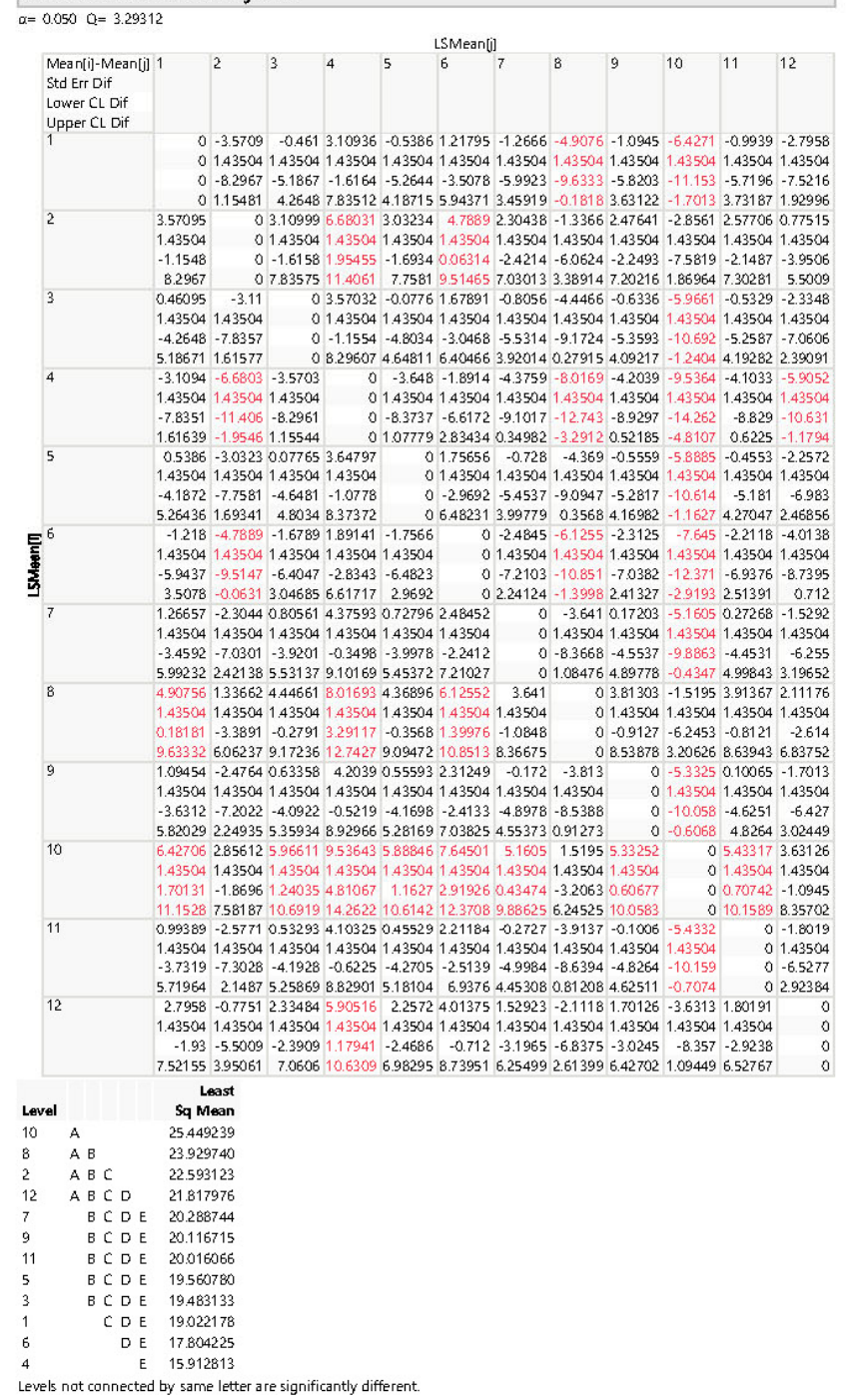




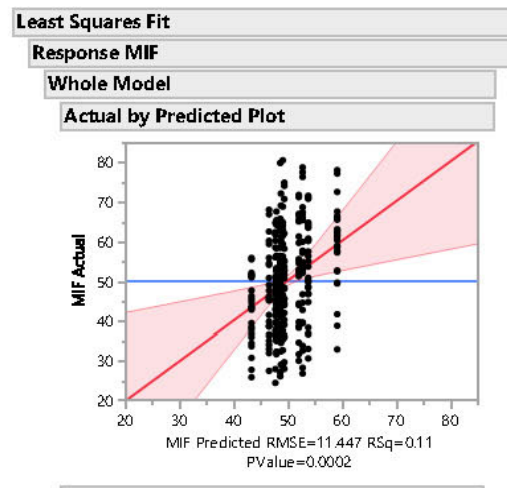

Effect Tests

Activity

Leverage Plot

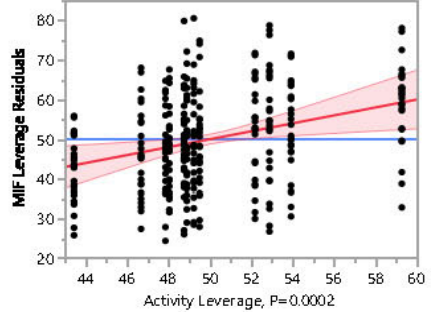

LSMeans Differences Tukey HSD

$\alpha=0.050 \mathrm{Q}=3.29312$

Source Nparm DF Squares F Ratio Prob $>$ F

$\begin{array}{lllllll}\text { Activity } & 11 & 11 & 4867.3434 & 3.3770 & 0.0002 *\end{array}$

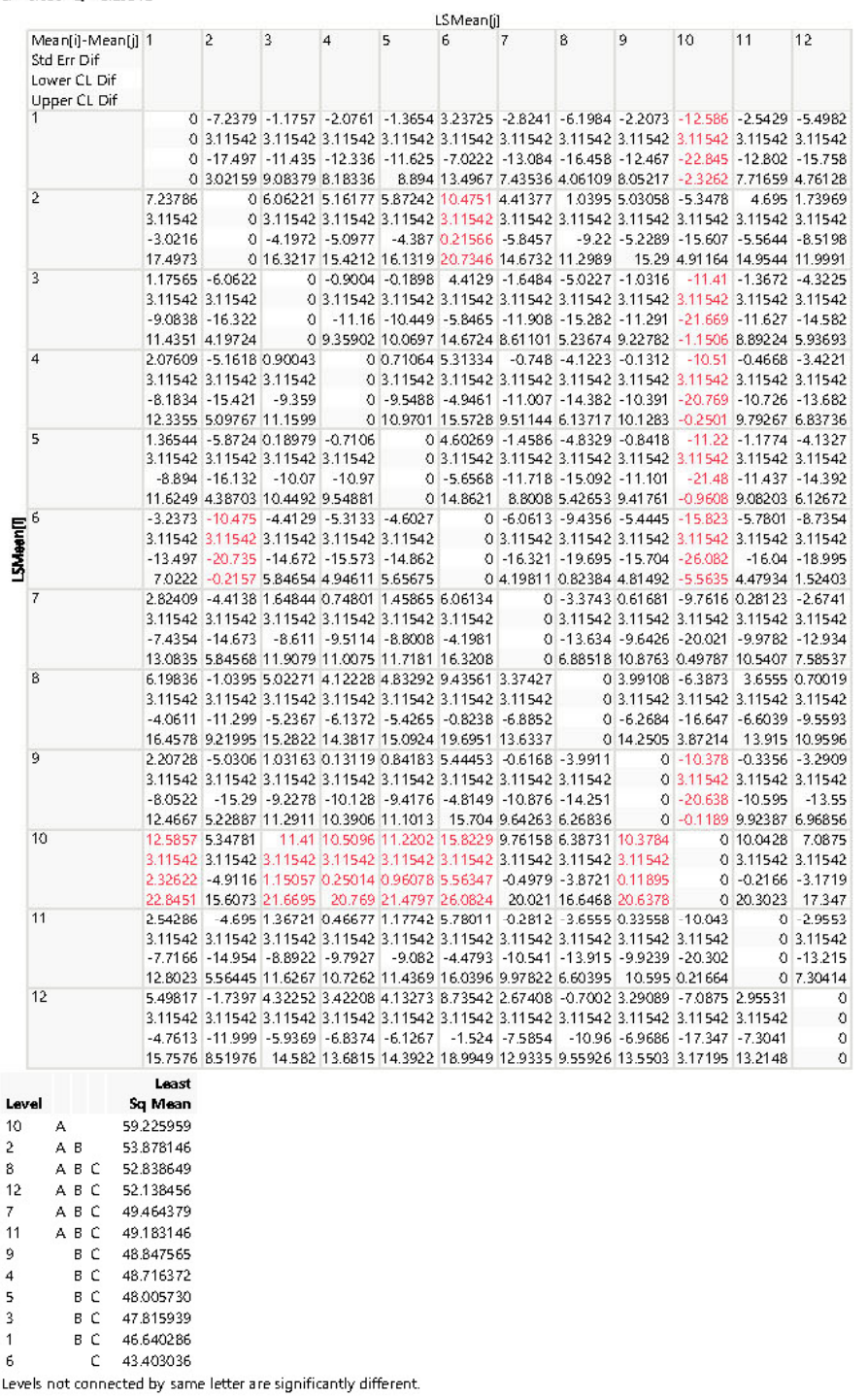




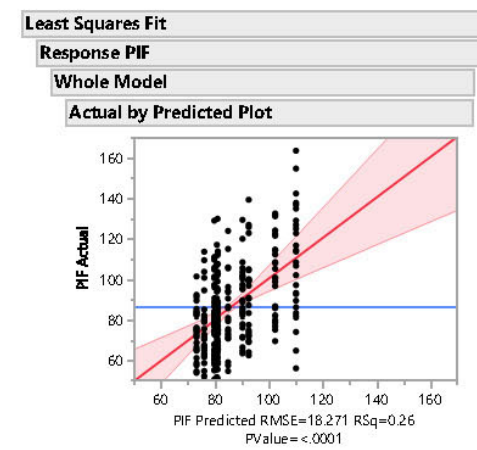

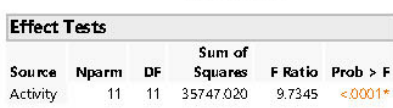

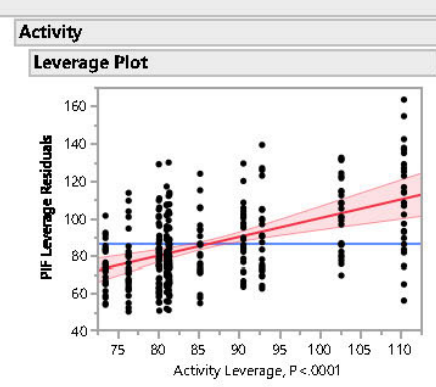

LSMeans Differences Tukey HSD
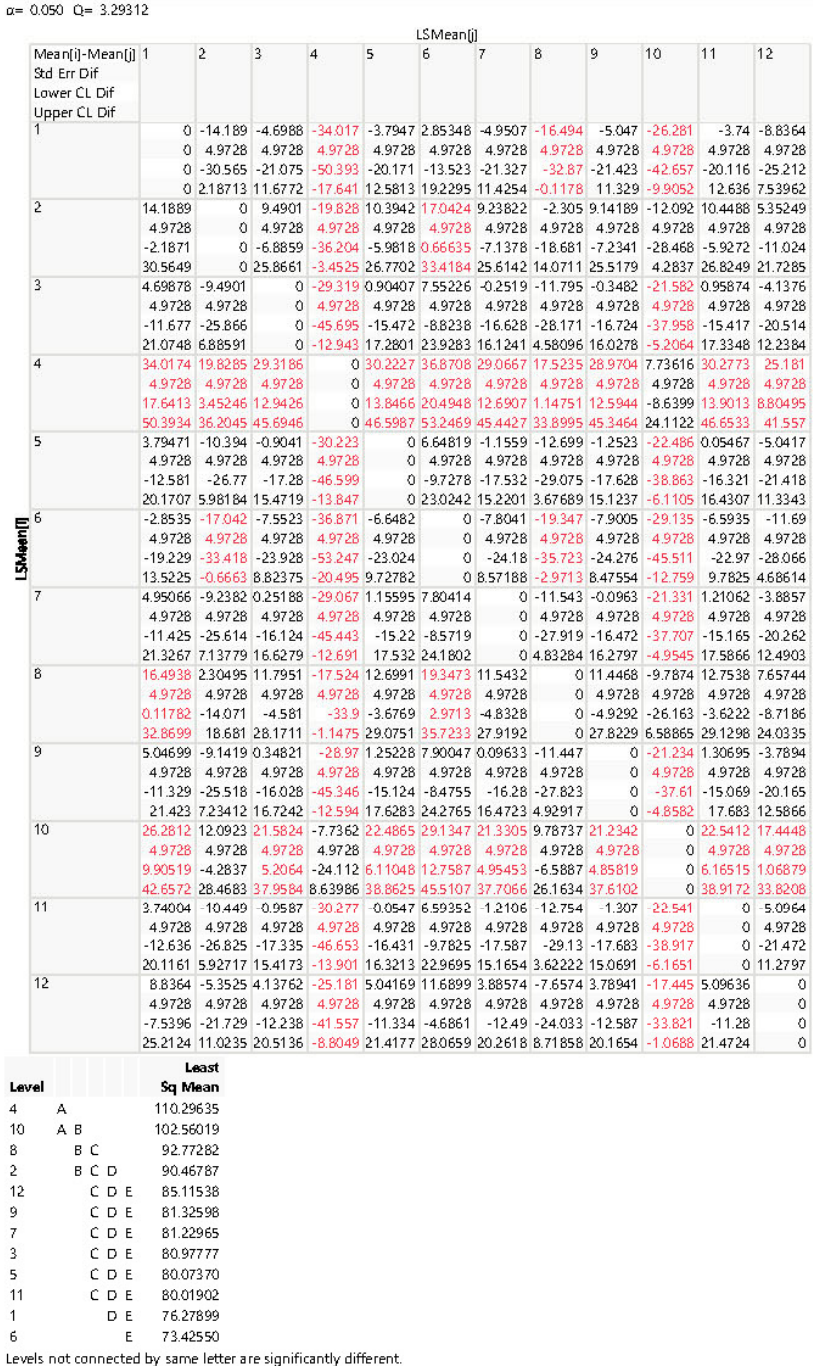


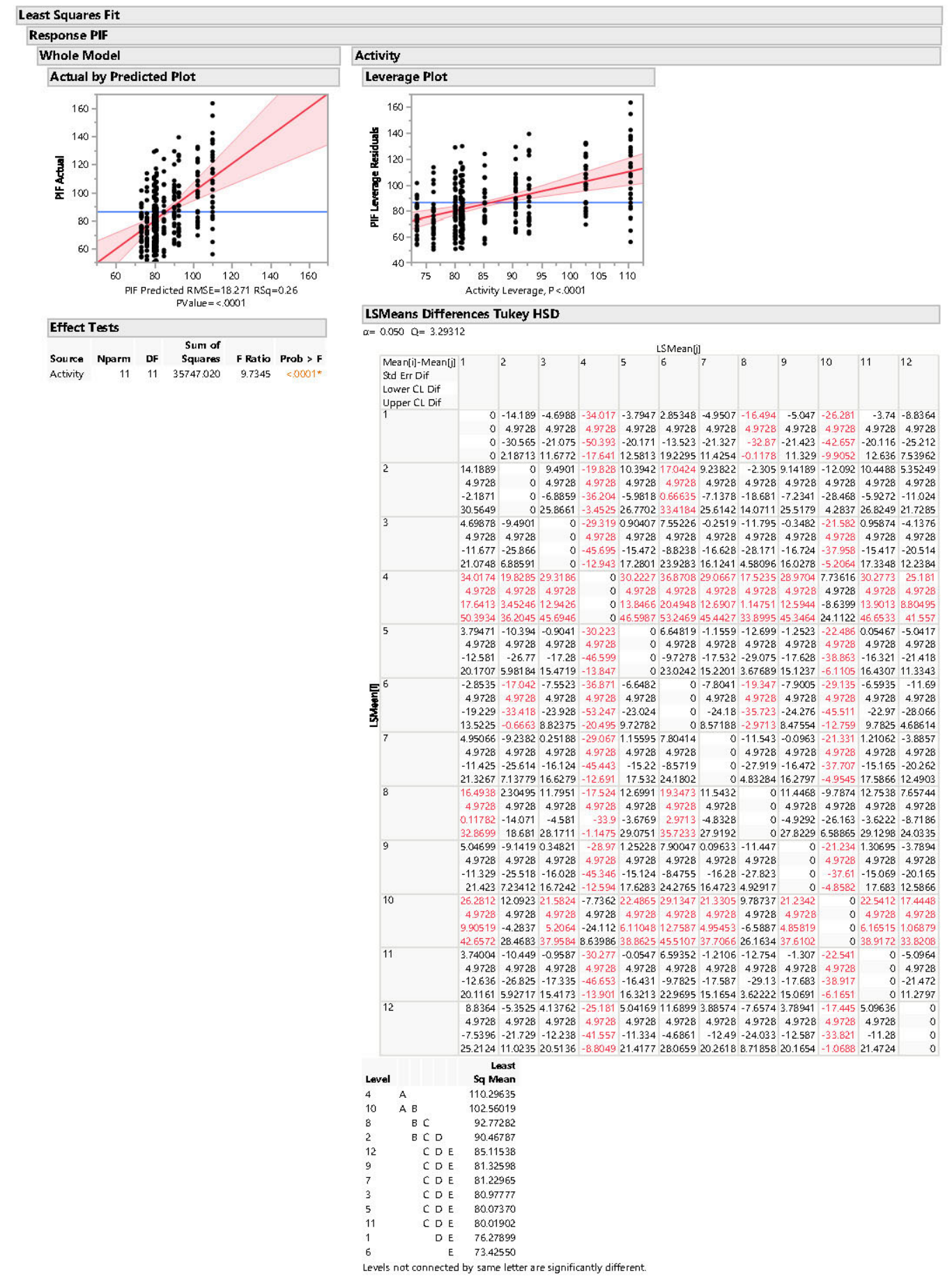



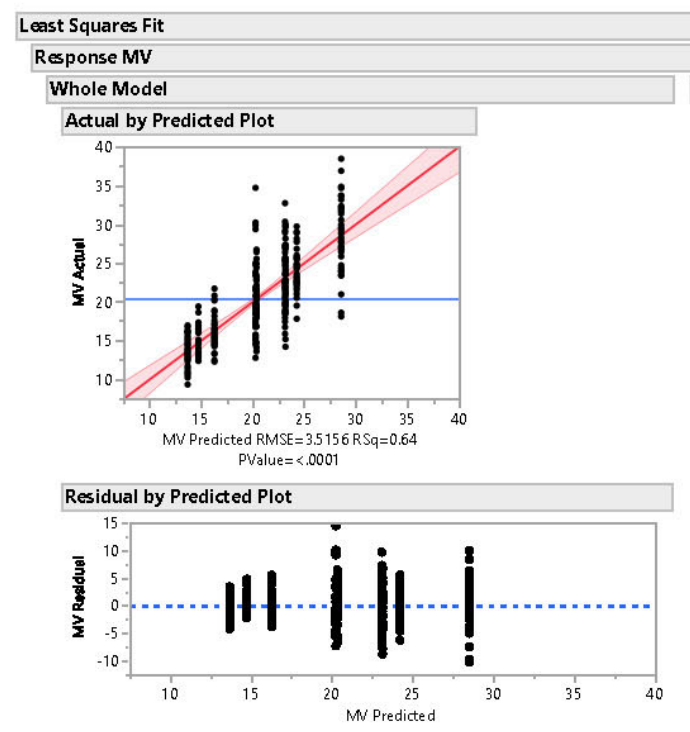

\begin{tabular}{|c|c|c|c|c|}
\hline \multicolumn{5}{|c|}{ Analysis of Variance } \\
\hline Source & DF & $\begin{array}{r}\text { Sum of } \\
\text { Squares }\end{array}$ & Mean Square & FRatio \\
\hline Model & 8 & 6811.435 & 851.429 & 68.8892 \\
\hline Error & 315 & 3893.209 & 12.359 & Prob $>F$ \\
\hline C. Total & 323 & 10704.644 & & $<.0001^{*}$ \\
\hline \multicolumn{5}{|c|}{ Effect Tests } \\
\hline & & DF & $\begin{array}{l}\text { Sum of } \\
\text { Squares }\end{array}$ & latio $\mathrm{Pr}$ \\
\hline Participan & & 8 & 811.4345 & $8892<.00$ \\
\hline
\end{tabular}

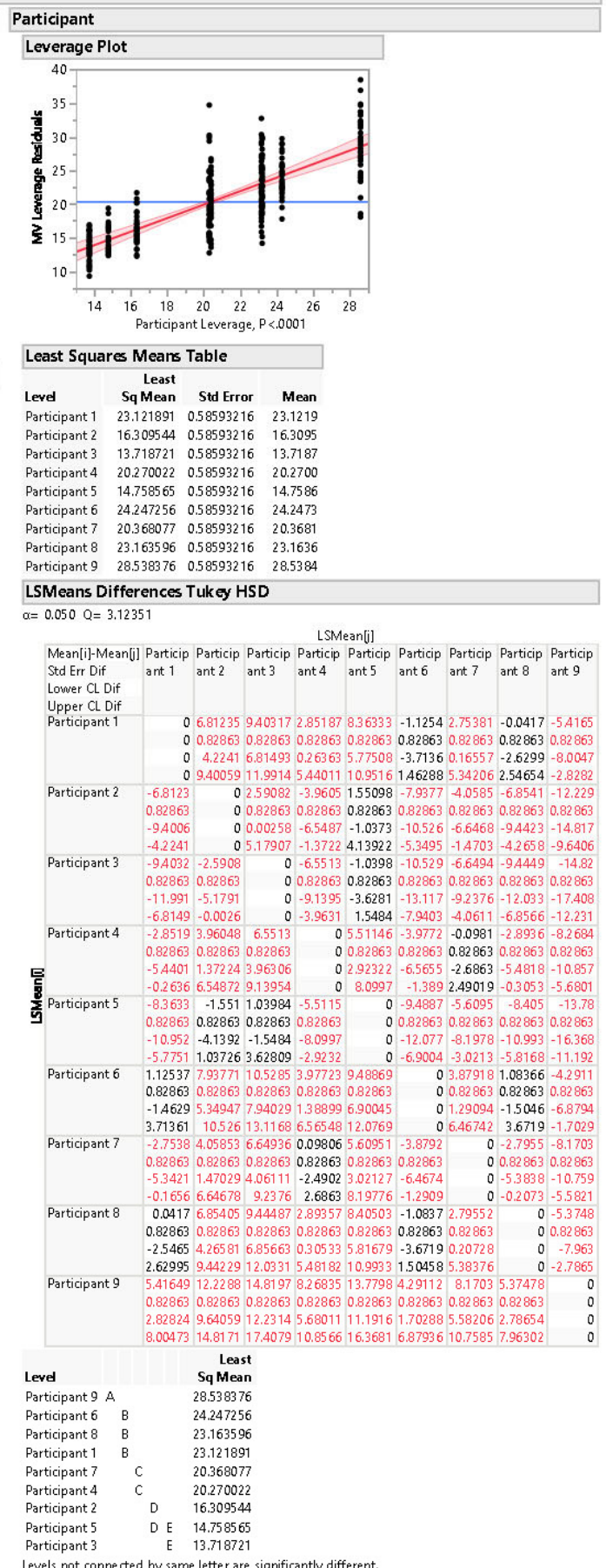




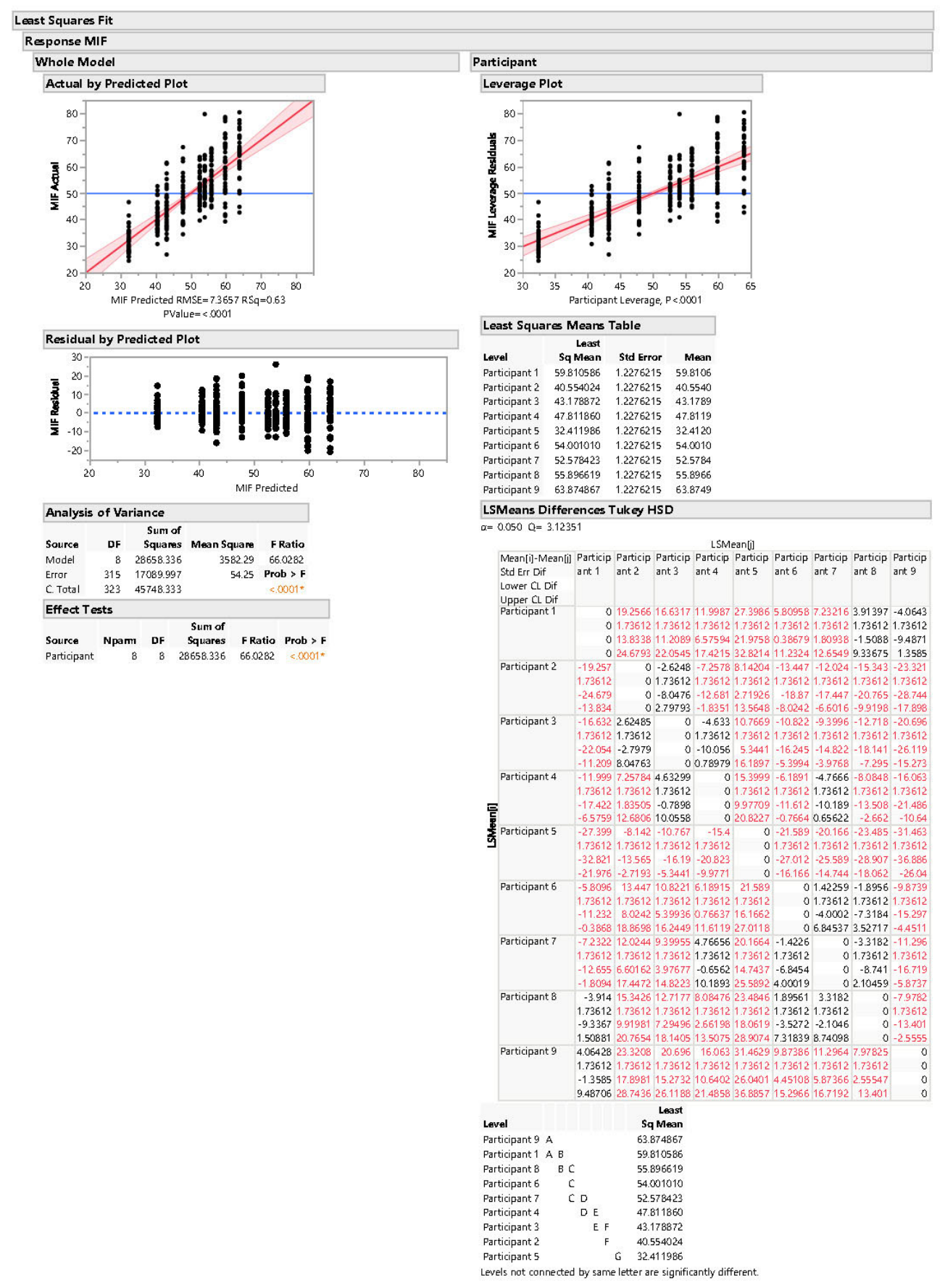



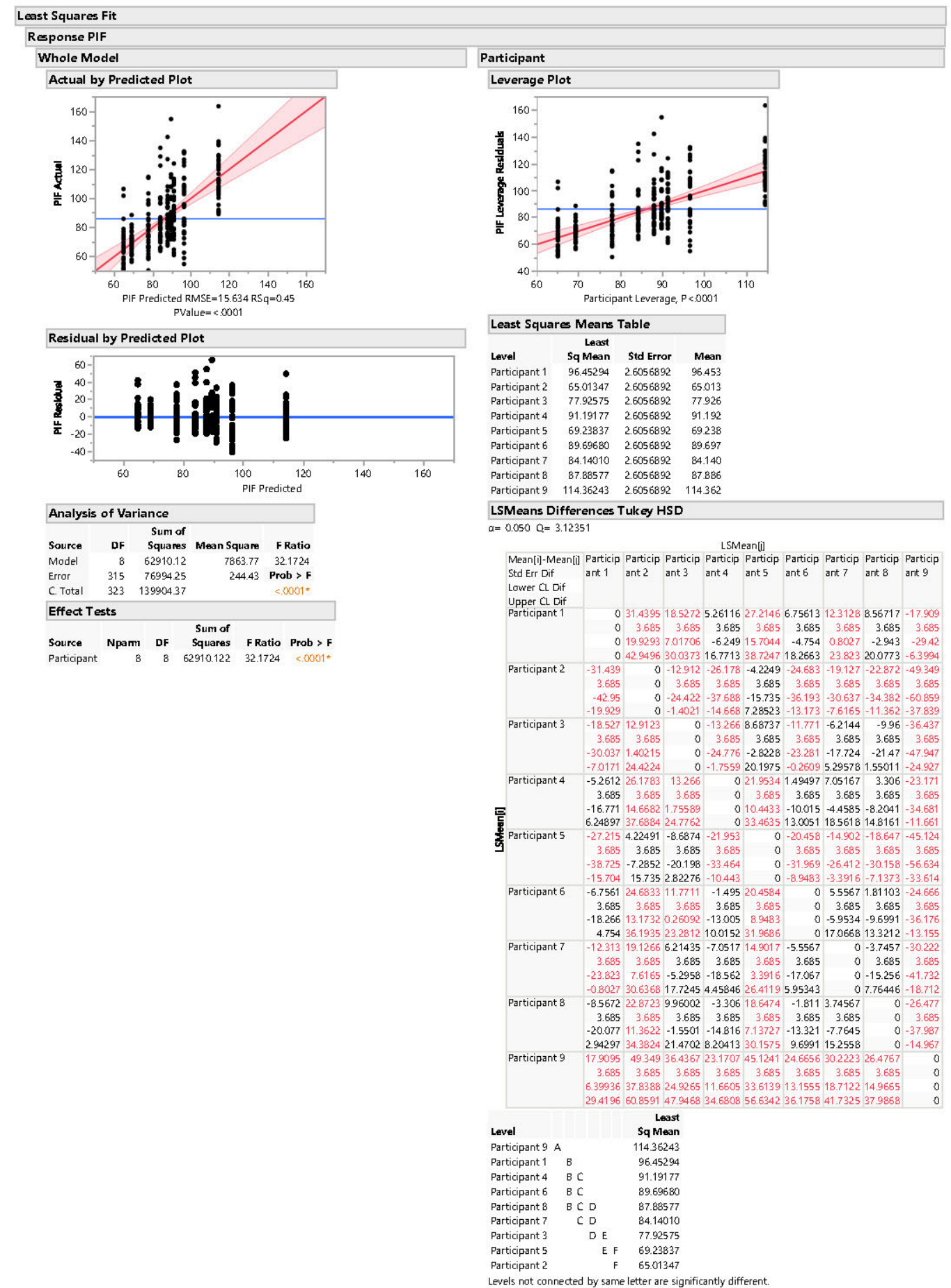
Appendix B: Additional Respiratory Flow Data Graphs

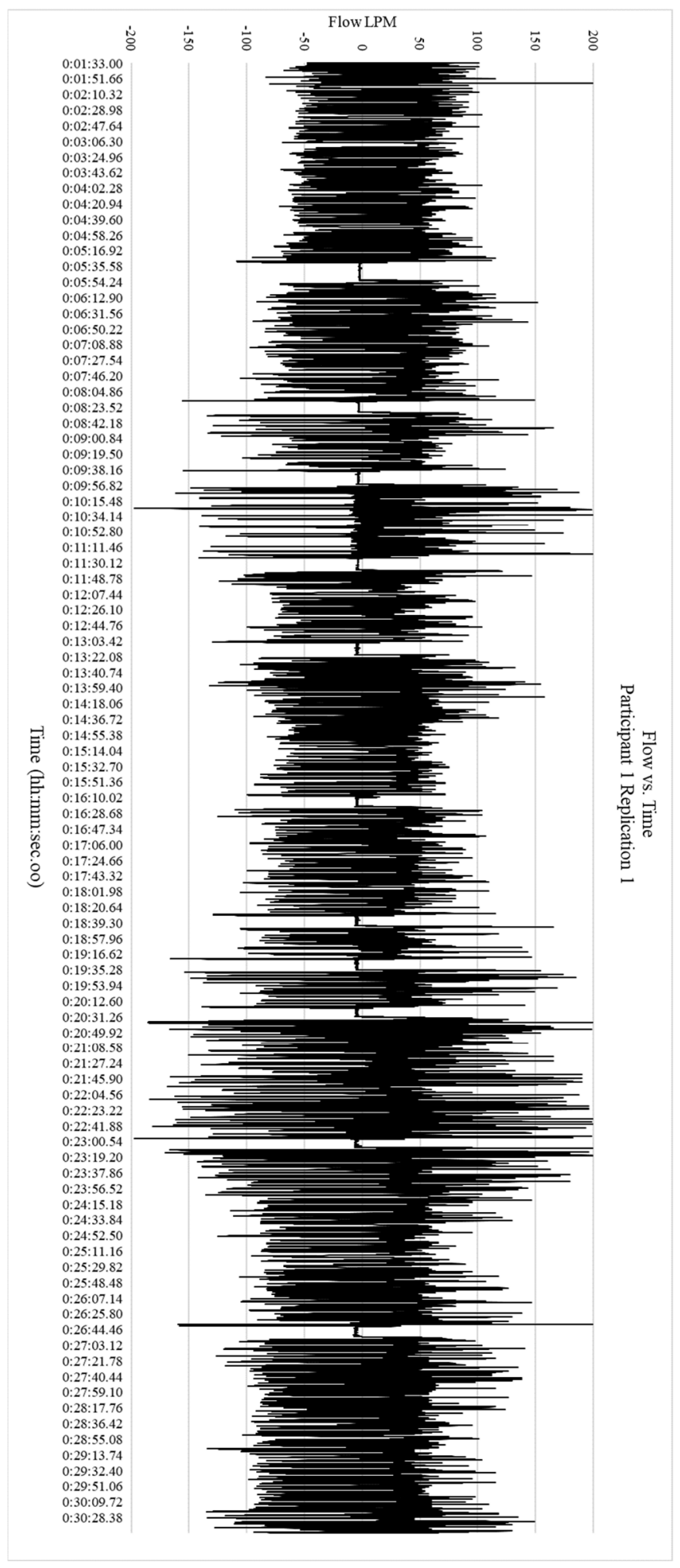




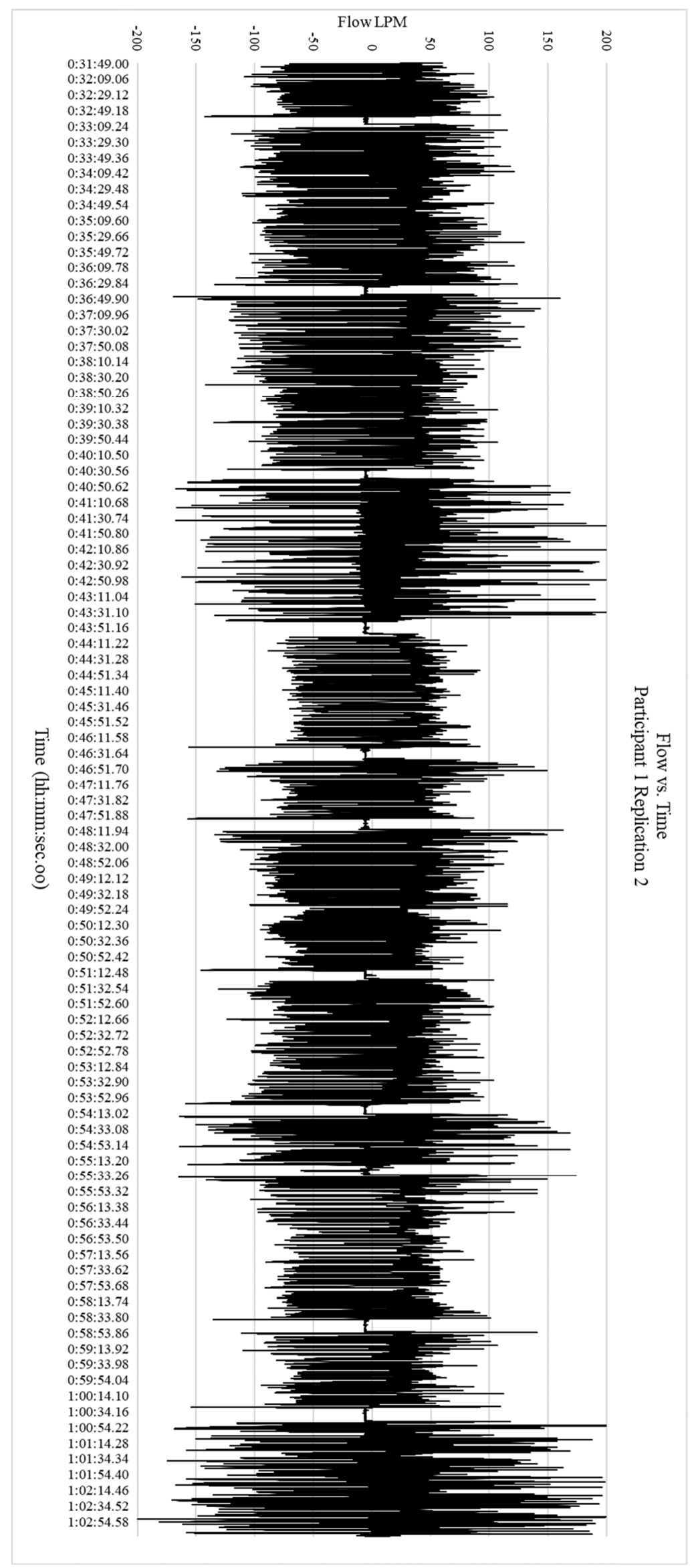




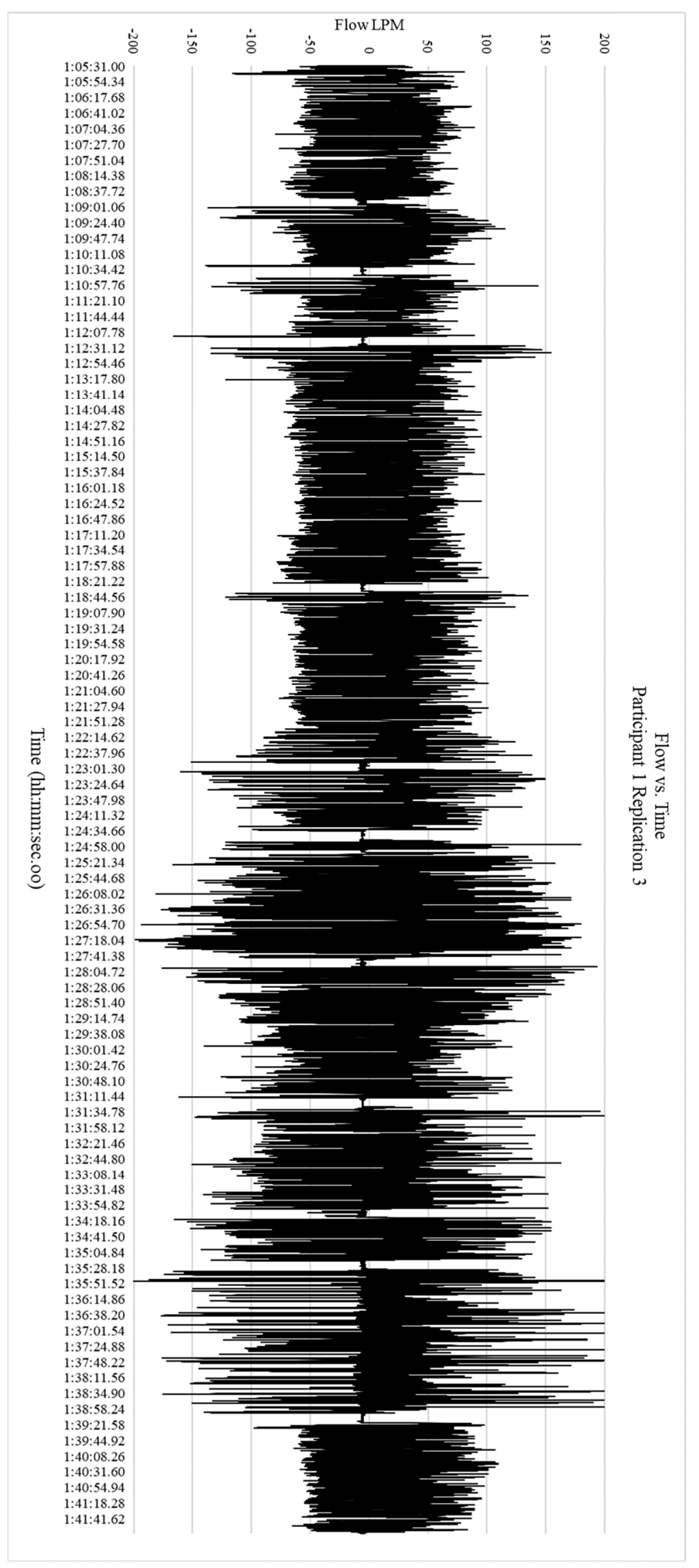




\section{Appendix C: Fit Test Results}

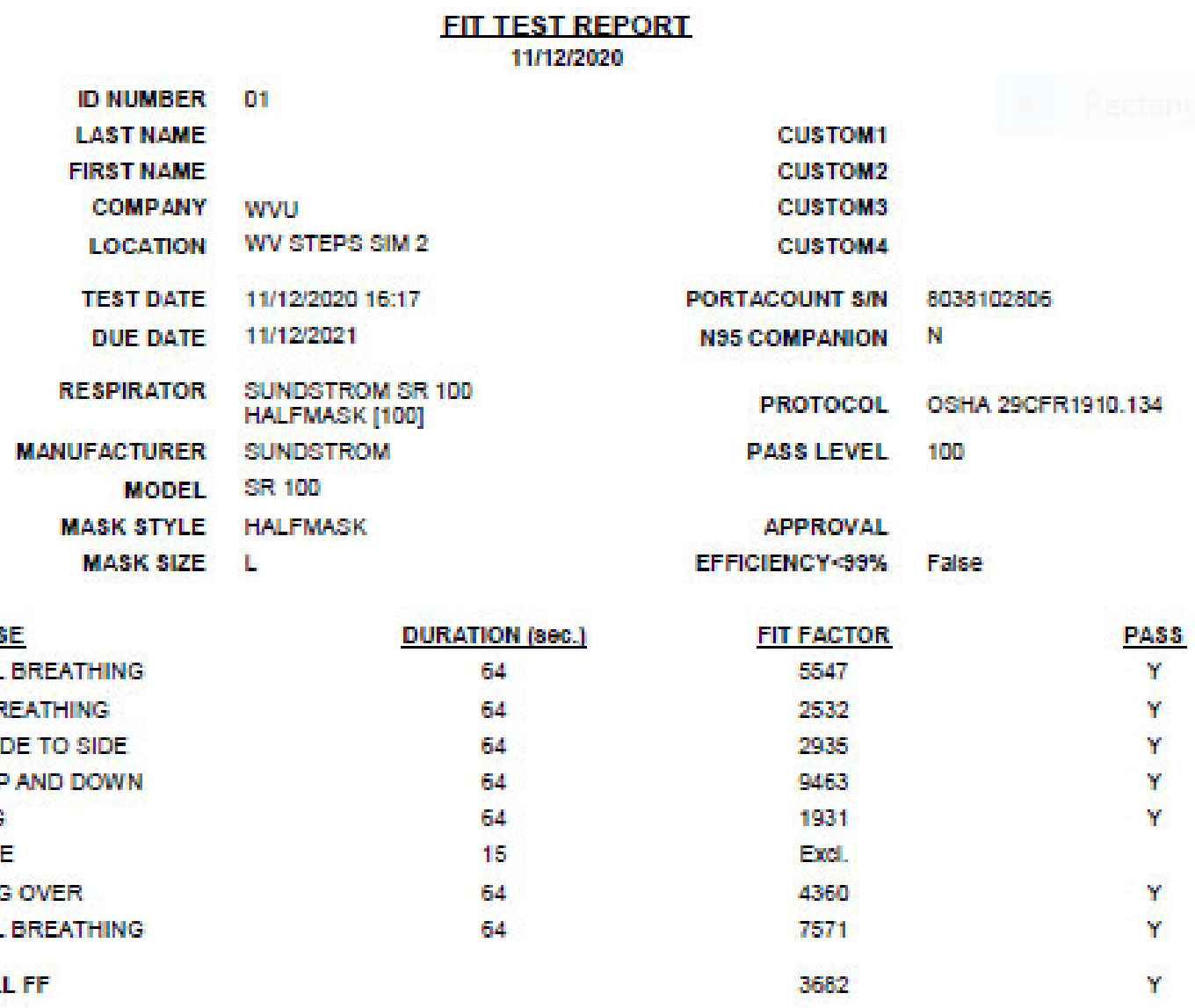


FII TEST REPQRI

$11 / 16 / 2020$

$\begin{aligned} \text { ID NUMBER } & 02 \\ \text { LAST NAME } & \\ \text { FIRST NAME } & \\ \text { COMPANY } & \text { WVU } \\ \text { LOCATION } & \text { WV STEPS SIM } 2 \\ \text { TEST DATE } & 11 / 16 / 202016: 30 \\ \text { DUE DATE } & 11 / 16 / 2021 \\ & \\ \text { RESPIRATOR } & \text { SUNDSTROM SR 100 } \\ \text { MANUFACTURER } & \text { HALFMASK [100] } \\ \text { MODEL } & \text { SR 100 } \\ \text { MASK STYLE } & \text { HALFMASK } \\ \text { MASK SIZE } & \text { SM }\end{aligned}$

EXERCISE

NORMAL BREATHING

DEEP BREATHING

HEAD SIDE TO SIDE

HEAD UP AND DOWN

TALKING

GRIMACE

BENDING OVER

NORMAL BREATHING

OVERALL FF

\section{DURATION (sec.)}

64

64

64

64

64

15

64

64

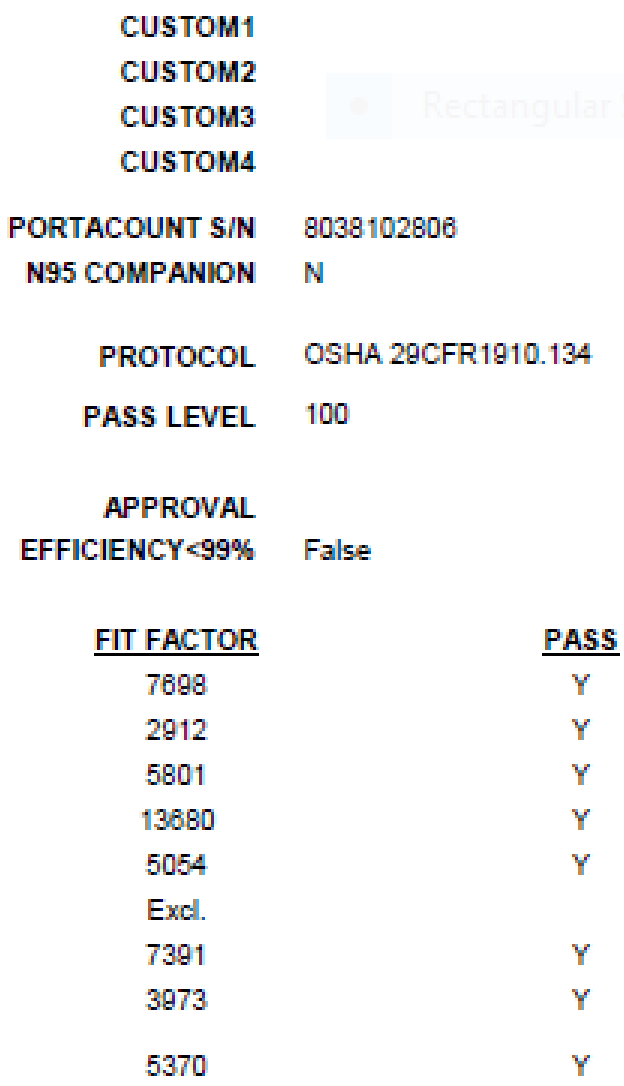




\section{EII TEST REPORI}

$11 / 06 / 2020$

$\begin{aligned} \text { ID NUMBER } & 08 \\ \text { LAST NAME } & \\ \text { FIRST NAME } & \\ \text { COMPANY } & \text { WVU } \\ \text { LOCATION } & \text { WV STEPS SIM } 2 \\ \text { TEST DATE } & 11 / 6 / 202016: 15 \\ \text { DUE DATE } & 11 / 6 / 2021 \\ \text { RESPIRATOR } & \text { SUNDSTROM SR 100 } \\ \text { MANUFACTURER } & \text { HALFMASK [100] } \\ \text { MODEL } & \text { SR 100 } \\ \text { MASK STYLE } & \text { HALFMASK } \\ \text { MASK SIZE } & \text { L }\end{aligned}$

\section{EXERCISE}

DURATION (sec.)

NORMAL BREATHING

DEEP BREATHING

HEAD SIDE TO SIDE

HEAD UP AND DOWN

TALKING

GRIMACE

BENDING OVER

NORMAL BREATHING

64

64

64

64

64

15

64

64

OVERALL FF

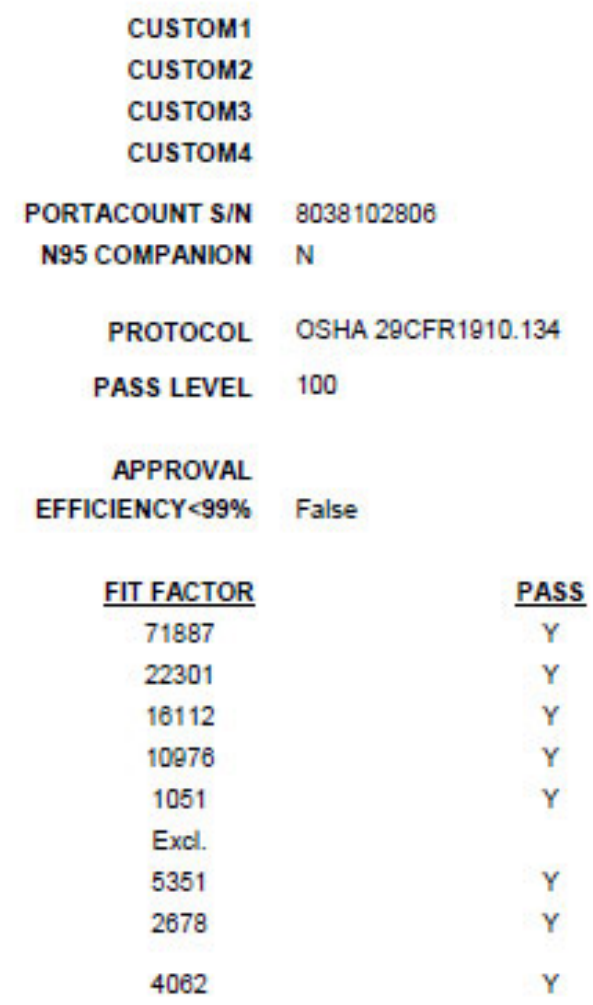

PORTACOUNT S/N 8038102806

N95 COMPANION N

PROTOCOL OSHA 29CFR1910.134
PASS

$\mathrm{Y}$

$Y$

$Y$

$Y$

$Y$

Y 


\section{FIT TEST REPORT}

$11 / 10 / 2020$

$\begin{aligned} \text { ID NUMBER } & 06 \\ \text { LAST NAME } & \\ \text { FIRST NAME } & \\ \text { COMPANY } & \text { WVU } \\ \text { LOCATION } & \text { WV STEPS SIM } 2 \\ \text { TEST DATE } & 11 / 10 / 202018.45 \\ \text { DUE DATE } & 11 / 10 / 2021 \\ \text { RESPIRATOR } & \text { SUNDSTROM SR 100 } \\ & \text { HALFMASK [100] } \\ \text { MANUFACTURER } & \text { SUNDSTROM } \\ \text { MODEL } & \text { SR 100 } \\ \text { MASK STYLE } & \text { HALFMASK } \\ \text { MASK SIZE } & \text { L }\end{aligned}$

\section{EXERCISE}

NORMAL BREATHING

DEEP BREATHING

HEAD SIDE TO SIDE

HEAD UP AND DOWN

TALKING

GRIMACE

BENDING OVER

NORMAL BREATHING

OVERALL FF

\section{DURATION (sec.)}

64

64

64

84

64

15

64

64

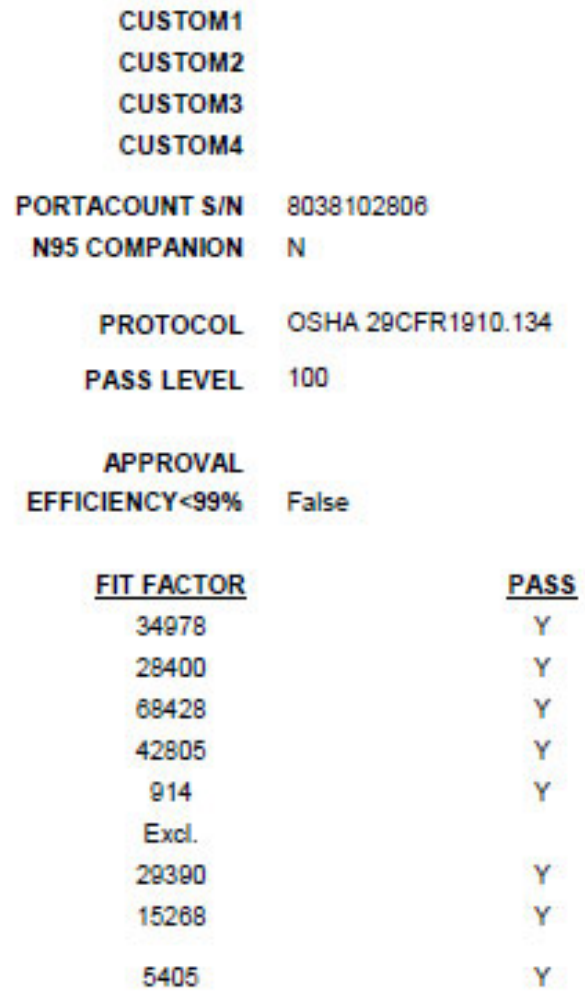


EII TEST REPQRI

11/03/2020

$\begin{array}{rll}\text { ID NUMBER } & 05 \\ \text { LAST NAME } & \\ \text { FIRST NAME } & \\ \text { COMPANY } & \text { WVU } \\ \text { LOCATION } & \text { WV STEPS SIM } 2 \\ \text { TEST DATE } & 11 / 3 / 202019: 07 \\ \text { DUE DATE } & 11 / 3 / 2021 \\ \text { RESPIRATOR } & \text { SUNDSTROM SR 100 } \\ \text { MANUFACTURER } & \text { SULFMASK [100] } \\ \text { MODEL } & \text { SR 100 } \\ \text { MASK STYLE } & \text { HALFMASK } \\ \text { MASK SIZE } & \text { L }\end{array}$

EXERCISE

NORMAL BREATHING

DEEP BREATHING

HEAD SIDE TO SIDE

HEAD UP AND DOWN

TALKING

GRIMACE

BENDING OVER

NORMAL BREATHING

OVERALL FF

\section{DURATION (sec.)}

64

64

64

64

64

15

64

64

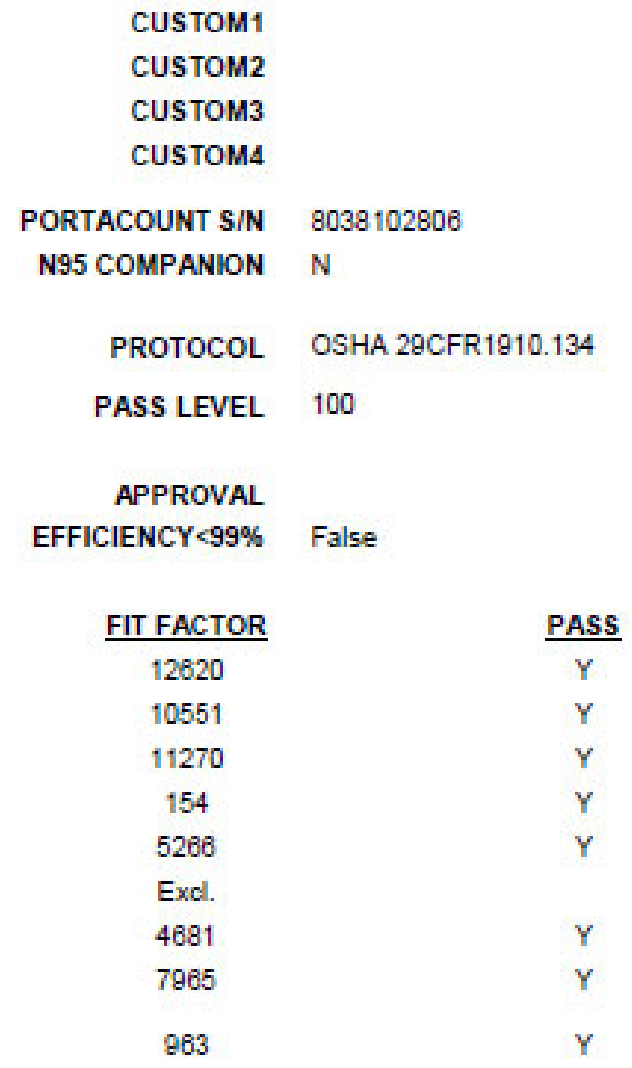




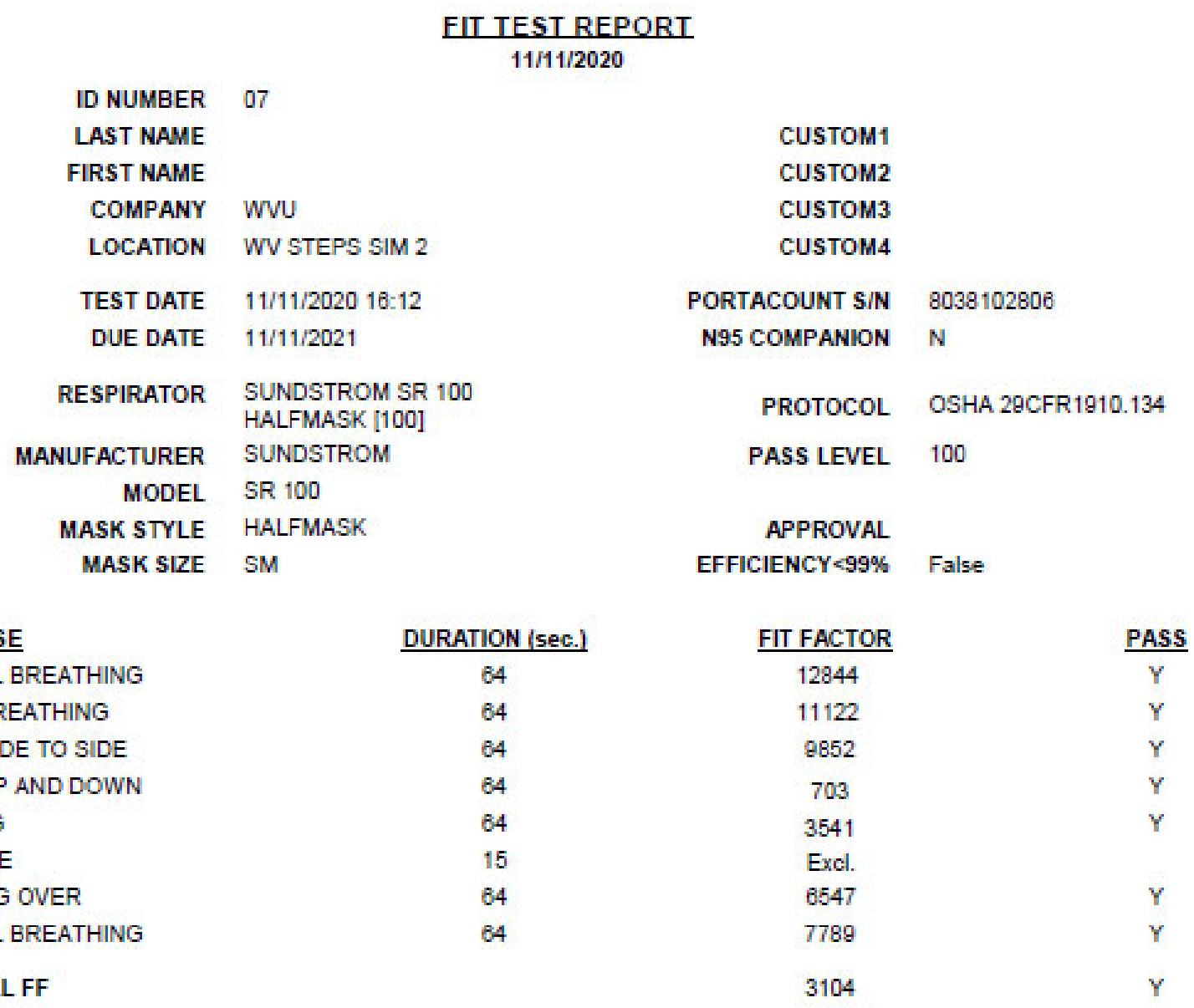




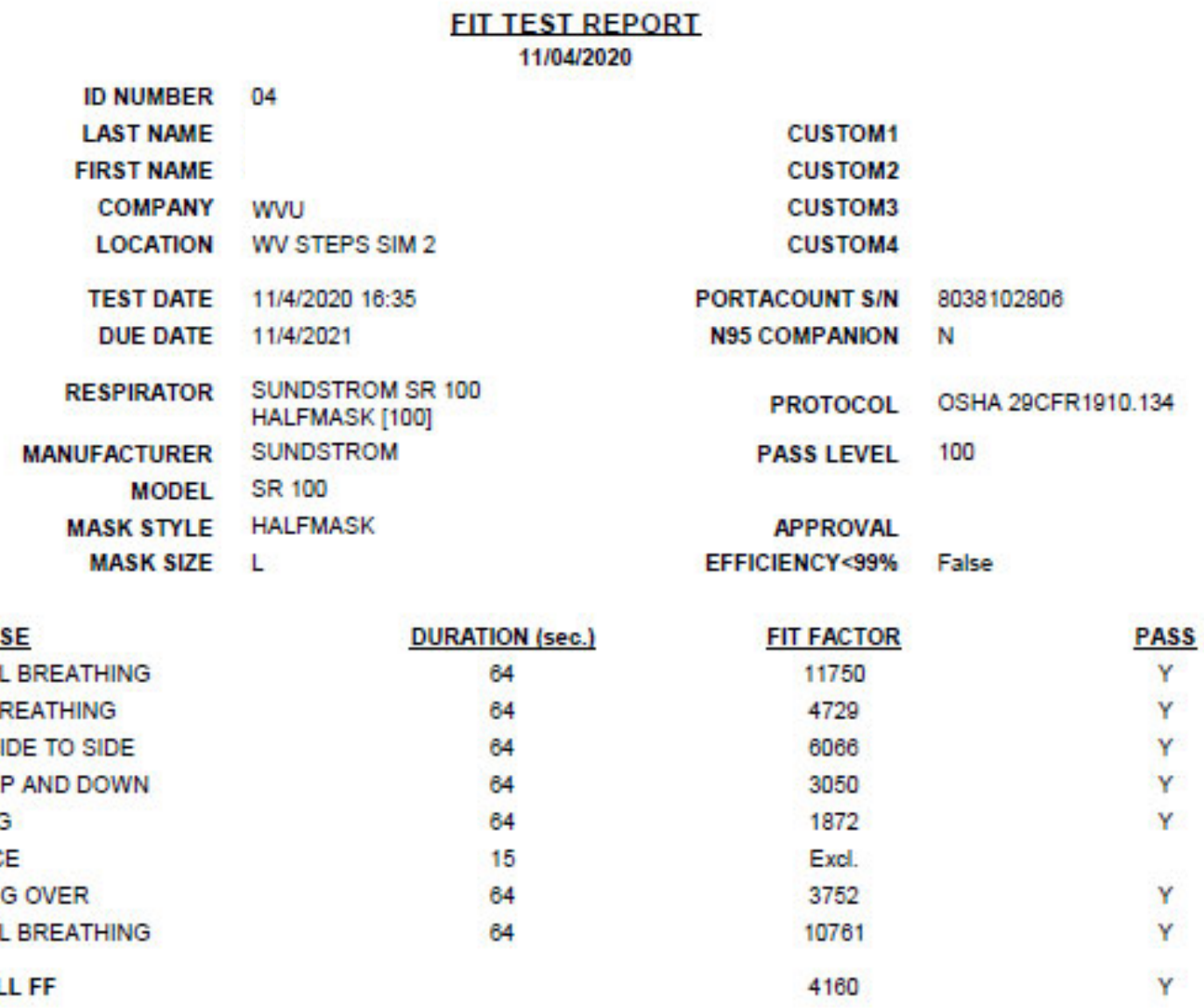




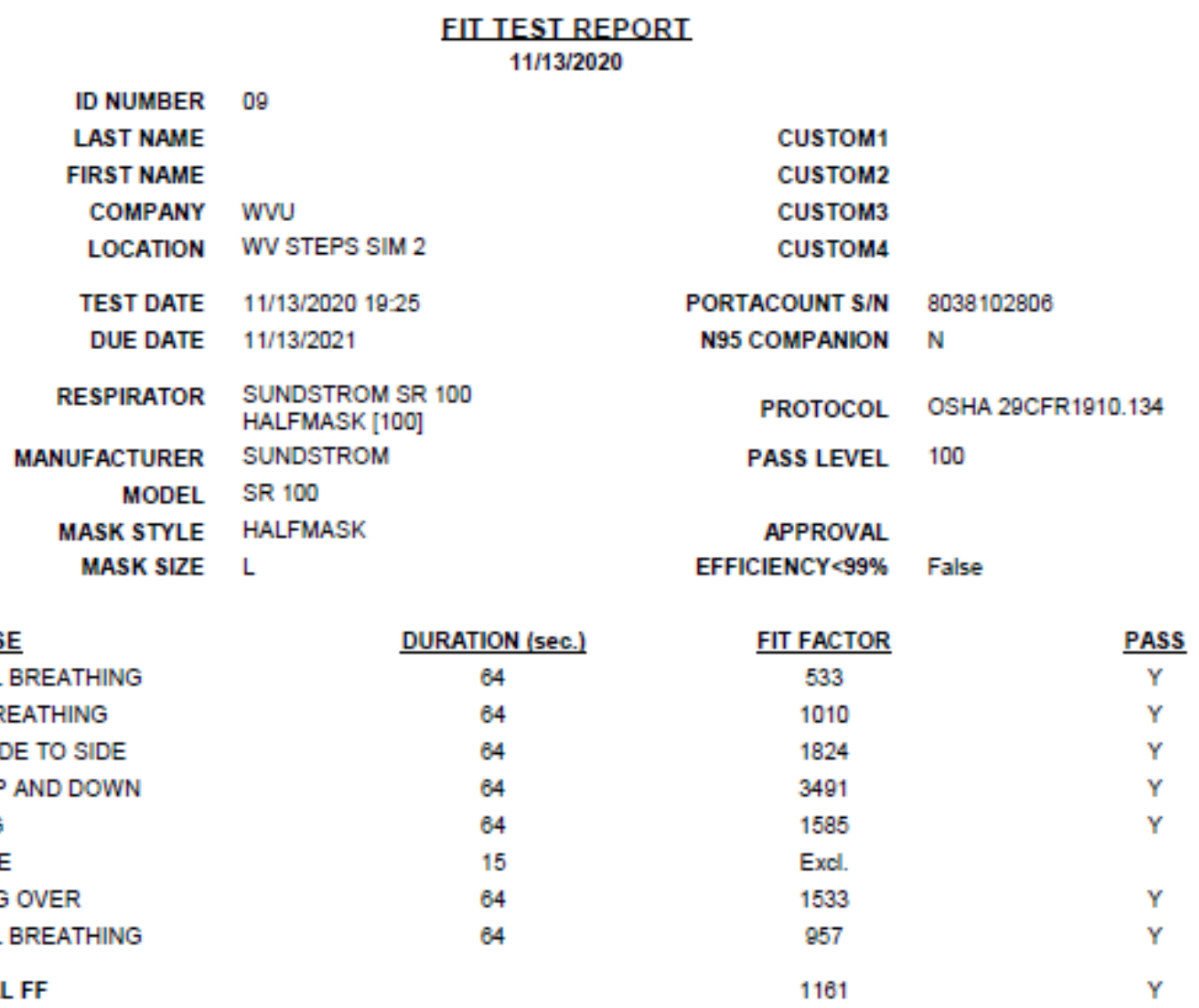




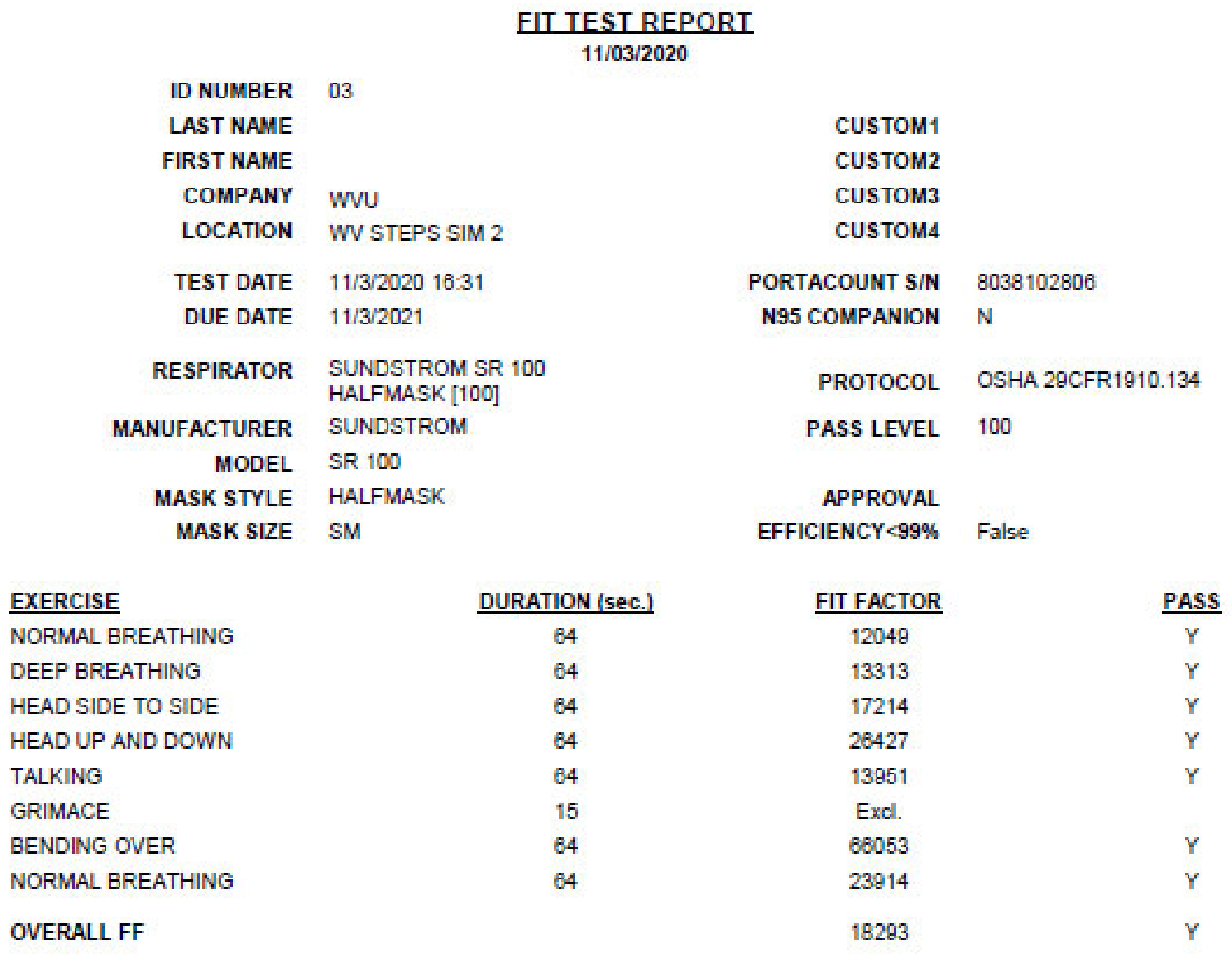

